OPEN ACCESS

Edited by:

Magnus Gram,

Lund University, Sweden

Reviewed by:

Jozsef Balla

University of Debrecen, Hungary

Bo Akerstrom

Lund University, Sweden

Joris Delanghe,

Ghent University, Belgium

${ }^{*}$ Correspondence:

Ann Smith

MBB-School of Biological Sciences, University of Missouri-Kansas City,

5007 Rockhill Road, Kansas, MO 64110, USA

smithan@umkc.edu

Specialty section:

This article was submitted to

Oxidant Physiology,

a section of the journal

Frontiers in Physiology

Received: 31 March 2015

Accepted: 11 June 2015

Published: 30 June 2015

Citation:

Smith A and McCulloh RJ (2015)

Hemopexin and haptoglobin: allies against heme toxicity from hemoglobin not contenders. Front. Physiol. 6:187.

doi: 10.3389/fphys.2015.00187

\section{Hemopexin and haptoglobin: allies against heme toxicity from hemoglobin not contenders}

\author{
Ann Smith ${ }^{1 *}$ and Russell J. McCulloh ${ }^{2,3}$ \\ ${ }^{1}$ School of Biological Sciences, University of Missouri-Kansas City, Kansas City, MO, USA, ${ }^{2}$ Pediatric and Adult Infectious \\ Diseases, Children's Mercy-Kansas City, Kansas City, MO, USA, ${ }^{3}$ School of Medicine, University of Missouri-Kansas City, \\ Kansas City, MO, USA
}

The goal here is to describe our current understanding of heme metabolism and the deleterious effects of "free" heme on immunological processes, endothelial function, systemic inflammation, and various end-organ tissues (e.g., kidney, lung, liver, etc.), with particular attention paid to the role of hemopexin (HPX). Because heme toxicity is the impetus for much of the pathology in sepsis, sickle cell disease (SCD), and other hemolytic conditions, the biological importance and clinical relevance of HPX, the predominant heme binding protein, is reinforced. A perspective on the function of HPX and haptoglobin ( $\mathrm{Hp})$ is presented, updating how these two proteins and their respective receptors act simultaneously to protect the body in clinical conditions that entail hemolysis and/or systemic intravascular (IVH) inflammation. Evidence from longitudinal studies in patients supports that HPX plays a Hp-independent role in genetic and non-genetic hemolytic diseases without the need for global $\mathrm{Hp}$ depletion. Evidence also supports that HPX has an important role in the prognosis of complex illnesses characterized predominantly by the presence of hemolysis, such as SCD, sepsis, hemolytic-uremic syndrome, and conditions involving IVH and extravascular hemolysis $(\mathrm{EVH})$, such as that generated by extracorporeal circulation during cardiopulmonary bypass (CPB) and from blood transfusions. We propose that quantitating the amounts of plasma heme, HPX, Hb-Hp, heme-HPX, and heme-albumin levels in various disease states may aid in the diagnosis and treatment of the above-mentioned conditions, which is crucial to developing targeted plasma protein supplementation (i.e., "replenishment") therapies for patients with heme toxicity due to HPX depletion.

Keywords: hemopexin, heme, haptoglobin, iron, plasma protein therapeutics, hemolytic index, hemolysis, erythrophagocytosis

\footnotetext{
Abbreviations: Mr, Apparent Molecular weight; CPB, Cardiopulmonary bypass; CD91/LRP1, CD163, Cluster of differentiation; DF, Dengue fever; DHF, Dengue hemorrhagic fever; EVH, Extravascular hemolysis; FLVCR, Feline leukemia virus Sub group C receptor; FPN, Ferroportin; Hp, Haptoglobin; HO, Heme oxygenase; HPX, Hemopexin; HIV, Human immunodeficiency virus; IVH, Intravascular hemolysis; IL-6, interleukin-6; MetHb, Methemoglobin; Mb, Myoglobin; NQO1, $\operatorname{NADP}(\mathrm{H})$ :quinone oxido-reductase 1; NET, Neutrophil extracellular trap; NO, Nitric oxide; NOS, Nitric oxide synthase; PMVEC, Pulmonary artery endothelial cell; PMVEC, Pulmonary microvasculature endothelial cell; PHP, pyridoxalated Hb polyoxethylene conjugate; ROS, Reactive oxygen species; RBC, red blood cell; SCD, Sickle cell disease; TNF, tumor necrosis factor; VWF, Von Willibrand Factor.
} 


\section{Introduction}

The low, essentially constant leakage of hemoglobin $(\mathrm{Hb})$ from red blood cells (RBCs), termed trivial hemolysis, is well-tolerated; however, both intravascular (IVH) and extravascular (EVH) hemolysis induce severe inflammation and potential tissue dysfunction. This pathology is due to heme (iron-protoporphyrin IX) released from methemoglobin (metHb, Bunn and Jandl, 1968). Unless bound to proteins, the redox-active heme-iron participates in oxygen radical reactions that covalently modify protein, lipid, carbohydrate and/or nucleotides, which then lead to tissue damage. Cellular heme toxicity, first described in 1991 (Balla et al., 1991b), derives partly from heme alone and also through heme-mediated sensitization of cells to subsequent stimuli including reactive oxygen species from activated human neutrophils, inflammatory cytokines, and NO. Cells rely on "extracellular antioxidants," i.e., the proteins in biological fluids to prevent such radical chemistry by sequestering the heme and its iron (Halliwell and Gutteridge, 1990). Thus, haptoglobin (Hp) binds $\mathrm{Hb}$, the source of heme that is bound by hemopexin (HPX), and transferrin binds iron. In plasma, HPX targets heme to the liver parenchymal cells for heme catabolism, iron storage, and re-distribution. In barrier tissues, HPX targets heme to brain neurons (Hahl et al., 2013). Normally, HPX recycles after heme delivery whereas the $\mathrm{Hp}-\mathrm{Hb}$ complex is degraded in macrophages. Documented changes in plasma $\mathrm{Hp}$ and free $\mathrm{Hb}$ levels provide clues as to the extent of hemolysis; but only HPX and heme levels demonstrate problems with heme clearance.

Our purpose is to provide a new perspective on the roles of the HPX and Hp systems in human diseases in which they protect against $\mathrm{Hb}$-derived heme toxicity and body iron loss. HPX is not an acute phase protein in humans, as is $\mathrm{Hp}$, and because of additional differences between these systems in humans and in mice, we focus on reviewing in vivo data from human subjects and rhesus monkey research, and in vitro data from cultured human cells. Throughout this review, we have used italic font to emphasize key points and conclusions.

Our goal is to describe current understanding of heme metabolism and the deleterious effects of "free" heme on immunological processes, endothelial function, systemic inflammation, and various end-organ tissues (e.g., kidney, lung, liver, etc.), with particular attention paid to the protective role of HPX. We propose that the model of a linear pathway for the development of heme toxicity with HPX as a backup system for $\mathrm{Hp}$, i.e., acting only when $\mathrm{Hp}$ becomes depleted, does not represent many situations in vivo. Examples from patients and experimental animals provide evidence that HPX and $\mathrm{Hp}$ act simultaneously in various niches of the body when hemolysis occurs, both in the presence or absence of infection and inflammation. HPX protects human endothelial (Balla et al., 1993) and hepatic parenchymal (Larsen et al., 2010) cells from direct heme toxicity and heme-sensitization (Balla et al., 1991b). HPX protects human macrophages by limiting the heme-mediated oxidation of lipoproteins (Camejo et al., 1998; Smith, 2013) generating lipid peroxide- and iron loaded-LDL (Balla et al., 1991a). Heme-mediated LDL oxidation contributes to the pathogenesis of atherosclerosis (Camejo et al., 1998; Jeney et al., 2002), heme being derived from ruptured plaques (Nagy et al., 2010) and LDL from the extracellular intima.

Interest in the protective role of HPX has rapidly increased during the past 5 years because the causative role of heme in the pathophysiology of sepsis, sickle cell disease (SCD), other hemolytic conditions and also in atherosclerosis (Balla et al., 1991a; Nagy et al., 2010) has become accepted (Larsen et al., 2010; Smith, 2011a,b; Ghosh et al., 2013; Schaer et al., 2013; Smith, 2013; Belcher et al., 2014; Schaer et al., 2014; Jung et al., 2015). Insights into how HPX acts in clinical IVH and EVH have been obtained primarily through primate, rat-, mouse-, and human-based studies. While HPX's role in protection against heme-mediated inflammation and oxidative damage is established, further studies are needed to confirm the Hp-independent activity of HPX in hemolysis in various clinical disease states in humans. We have therefore summarized and reviewed both historical and recent observations on the HPX and Hp systems in relevant human conditions and diseases. Finally, we propose future research avenues related to heme metabolism in human health and disease. These include quantitating the amounts of plasma heme, HPX, Hb-Hp, heme-HPX, and heme-albumin levels in various disease states to aid in the diagnosis and treatment of diseases prominently characterized by hemolysis and investigating the use of targeted plasma protein supplementation (i.e., "replenishment") therapies for patients with heme toxicity due to HPX depletion. Although not addressed here, $\alpha-1$ microglobulin binds heme and free radicals protecting particularly EVH sites (Akerstrom and Gram, 2014), and when infused minimized pre-eclampsia-like symptoms from $\mathrm{Hb}$ in perfused human placenta (May et al., 2011); and treated pre-eclampsia in sheep (Wester-Rosenlof et al., 2014).

\section{Structure and Function of Hemopexin and Haptoglobin and their Role in Heme and Hemoglobin Clearance in Intravascular Hemolysis}

The lysis of $1 \mathrm{ml}$ of blood containing 5 billion RBCs each with $\sim 289$ million $\mathrm{Hb}$ molecules (Sears, 1999) could release $\sim 1.45 \times$ $10^{18} \mathrm{Hb}$ molecules, which is 1000 -fold higher than $20 \mu \mathrm{M}$ plasma Hp molecules $\left(6.82 \times 10^{15}\right)$ in the immediate plasma $(550 \mu \mathrm{l})$. Given that total body plasma Hp would be $\sim 2.8 \times 10^{19}$ molecules (and HPX on average an additional $1.8 \times 10^{19}$ molecules if at $12.4 \mu \mathrm{M}$ (Drabkin, 1971), it is clear that $\mathrm{Hb}$ and heme loads can be massive. Endothelial cells lack HPX receptors (Smith and Morgan, 1979) and unregulated heme diffusion into and metabolism by these cells, estimated to be $\sim 60$ trillion cells in the human body (Aird, 2005), represents a formidable asset and heme "sink" but also a major target for heme toxicity.

The crystal structure of the equimolar heme-HPX complex (Paoli et al., 1999) reveals the unique coordination of heme that contributes to one of the highest affinities known, Kd less than pM (Hrkal et al., 1974). Thus, HPX is the key defense against the deleterious effects of heme on cells, particularly hepatic, immune system and endothelial cells. Heme rapidly dissociates from metHb that is quickly generated from $\mathrm{HbO}_{2} \mathrm{~A}$, 
even faster from sickle $\mathrm{Hb}$ (HbS; Hebbel et al., 1988) and also from $\mathrm{Hp}$-bound $\mathrm{Hb}$; particularly in the presence of $\mathrm{NO}$ and ROS including hypochlorous acid (Jeney et al., 2002), generated by the respiratory burst of neutrophils and macrophages at sites of inflammation. Ferro-Hb was relatively innocuous to porcine endothelial cells in serum-free medium, whereas ferri-heme, which readily released from globin to which it is bound less tightly was toxic (Balla et al., 1993). The heme globin interaction is stronger in cyano- $\mathrm{Hb}$ and in $\mathrm{Hp}-\mathrm{Hb}$ preventing heme uptake. HPX prevented the metHb toxicity (Balla et al., 1993). Heme sensitizes cells to inflammatory cytokines, e.g., tumor necrosis factor- $\alpha$ (TNF), which is toxic to human hepatocytes (Larsen et al., 2010), and murine peritoneal macrophages (Fortes et al., 2012); as well as to ROS including $\mathrm{H}_{2} \mathrm{O}_{2}$, which predisposes porcine (Balla et al., 1991b) and human umbilical (Jeney et al., 2002) endothelial cells to die. Two synergistic mechanism by which heme causes necrosis of murine peritoneal macrophages are: TNF expression from TLR4/Myd88 pathway activation and TLR4-independent generation of ROS (Fortes et al., 2012). Micromolar heme activates human neutrophils triggering the oxidative burst and release of the chemokine interleukin 8 (Graca-Souza et al., 2002), resulting in leukocyte migration into tissues. In mice models of SCD, unless HPX is present or replenished, heme causes endothelial cells to present surface adhesion molecules leading to stasis and vasoocclusion in part via toll-like receptor-4 (TLR4) activation (Belcher et al., 2014) and pulmonary endothelia to produce neutrophil extracellular traps (Chen et al., 2014). Also, HPX down-regulates lipopolysaccharide (LPS)-induced production of TNF and IL-6 inflammatory cytokines in mouse bone marrowderived macrophages (Liang et al., 2009).

Within RBCs, heme in $\mathrm{Hb}$ is maintained in the reduced state needed for oxygen binding. After lysis, this ferro- $\mathrm{O}_{2} \mathrm{Hb}$ is bound by $\mathrm{Hp}$, then ferro- $\mathrm{Hb}-\mathrm{Hp}$ and, finally, ferric- $\mathrm{Hb}-\mathrm{Hp}$ complexes are generated. For $\mathrm{Hb}$ transport, each $\mathrm{Hp}$ molecule binds the equivalent of one tetramer of $\mathrm{Hb}\left[(\alpha \beta)_{4}\right]$, as two $\alpha \beta$ globin dimers each monomer with its own heme bound (Andersen et al., 2012). Hp sequesters $\mathrm{Hb}\left[\mathrm{Kd} 10^{-15} \mathrm{M}\right.$ (Lim et al., 2001)] limiting $\mathrm{Hb}$ oxidation with heme release unless ROS are present In humans, $\mathrm{Hp}-\mathrm{Hb}$ complexes are endocytosed by the cluster of differentiation receptor 163 (CD163) in mature tissue macrophages present in the spleen, liver, lymph nodes, bone marrow, lung, placenta, peritoneum, thymus, and the Kupffer cells of the liver.

Differences between the affinity of human and mouse CD163 for their respective $\mathrm{Hb}-\mathrm{Hp}$ complexes and for $\mathrm{Hb}$ itself indicate that CD163 endocytosis of $\mathrm{Hp}-\mathrm{Hb}(\mathrm{Kd} 19 \mathrm{nM})$ rather than of $\mathrm{Hb}$ is preferred in humans in contrast to mice (Etzerodt et al., 2013). Nevertheless, the affinity of human CD163 for $\mathrm{Hb}$ (Kd $195 \mathrm{nM}$ ) is sufficiently high that the micromolar levels of $\mathrm{Hb}$ documented in hemolytic conditions would result in CD163$\mathrm{Hb}$ binding (Receptor occupancy under equilibrium conditions would be expected to be $50 \%$ with a ligand concentration at the $\mathrm{Kd}$ value, and more than $90 \%$ occupancy at $100 \times \mathrm{Kd}$ value). Furthermore, mice do not always make good models of certain human inflammatory conditions that accompany hemolysis including trauma, burns, and endotoxemia that have some degree of hemolysis (Seok et al., 2013).
In IVH, the safe clearance of heme and $\mathrm{Hb}$ from the plasma by receptor-mediated endocytosis is rapid: within $2-5 \mathrm{~min}$ for heme-HPX principally by liver parenchymal cells (Smith and Morgan, 1981) in part via CD91/LRP1 (Hvidberg et al., 2005); and within $10 \mathrm{~min}$ for $\mathrm{Hb}-\mathrm{Hp}$ complexes by macrophage CD163 (Delanghe and Langlois, 2001). Clearance will be impaired when these two scavenger receptors are saturated with any of their many known ligands; and also when Hp and HPX are depleted. Heme is then reserved on human serum albumin (HSA) from which it continuously dissociates. Non-protein bound heme travels at uncontrolled rates across the plasma membrane of cells via diffusion or possibly via channels or interacts with LDL.

The extracellular anti-oxidant protection of cells by HPX and $\mathrm{Hp}$ against heme toxicity from $\mathrm{Hb}$, along with their transport function, are only part of the protective responses against heme toxicity for the body. As first shown in 1992 (Balla et al., 1992), the high activities of two intracellular enzymatic systems are key to cell survival from heme toxicity by maintaining safe levels of redox-active heme and iron. Heme oxygenases (HOs) break down heme but in so doing release its iron as the tetrapyrrole ring opens. This chemically reactive iron is rapidly stored within the ferritin molecule via the ferroxidase activity of the $\mathrm{H}$ subunit. Heme and its iron can both be used for biochemical and regulatory purposes or exported. It is now known that heme and iron export systems (FLVCR and FPN1, respectively) and the acceptor proteins, HPX and transferrin, respectively, are also important. Regardless, survival against heme requires that cell metabolism is competent, not compromised in any way, and thus able to provide cofactors including oxygen, NADPH for $\mathrm{HOs}$ and obligatory reductases, and also for $\mathrm{H}$-ferritin. Resistance of porcine endothelial cells to heme toxicity and heme sensitization required chronic, rather than acute, exposure due to the induction of HO1, Ferritin, and particularly $\mathrm{H}-$ ferritin (Balla et al., 1992, 1993). Significantly, heme and its iron, respectively, are required for coordinate induction of $\mathrm{HO} 1$ and $\mathrm{H}$-ferritin. When $\mathrm{HO} 1$ is induced by chemical oxidative stress, cyto-protective ferritin is not induced, at least in murine macrophages (Sheftel et al., 2007). Notably, cellular metabolism is disturbed in severe illness, particularly sepsis (Langley et al., 2013, 2014; Tsalik et al., 2014), which limits the role of HO and ferritin among other protective mechanisms in mitigating oxidative damage.

\section{The Clinical Relevance of Hemoglobin, Hemopexin, and Haptoglobin Levels}

In humans, both HPX and Hp are developmentally regulated and hepatic synthesis is considered the predominant source of plasma protein. HPX is also produced in several immune-privileged sites including human brain neurons (Morris et al., 1993), neural retina photoreceptor cells, and ganglions (Chen et al., 1998); whereas $\mathrm{Hp}$ is in adipocytes, macrophages, and neutrophils ${ }^{1}$ and is induced by TNF- $\alpha$ in differentiated human adipocytes (Wang et al., 2005). As previously reviewed (Smith, 2011b),

\footnotetext{
${ }^{1}$ FDA Workshop on artificial hemoglobin. http://www.fda.gov/downloads/ BiologicsBloodVaccines/NewsEvents/WorkshopsMeetingsConferences/Transcript sMinutes/UCM051545.pdf.
} 
human HPX and Hp gene regulation have not been extensively studied. Both promoters contain sites and additional regulatory regions for the inflammatory cytokine, IL-6 (Poli et al., 1989) (but unlike Hp, HPX is not an acute phase reactant in humans). The HPX promoter drives brain and liver expression (Tolosano et al., 1996). Monkey and mouse HPX genes are regulated by heme (see Section Improving Animal Models of Human Disease in which Hemopexin and Haptoglobin Play a Protective Role Below). Human hepatoma HepG2 cells secrete Hp but not HPX. Human Hep3B cells may represent fetal, rather than adult, liver (Oliviero et al., 1987). Hp is induced by IL-6 in this line (Oliviero and Cortese, 1989) and also by IL- 1 but is independent of IL- 6 in HepG2 cells (Baumann et al., 1990).

HPX is very low in newborns and increases (in $\mathrm{mg} / 100 \mathrm{ml}$ ) from average of 60 (range 40-70) at 1-12 years to average of 77 (range 66-100) at 20-40 years but then declines at $50-70$ years (range 50-80, Hanstein and Muller-Eberhard, 1968).

The extent of IVH is clinically evaluated from the extent of plasma $\mathrm{Hp}$ depletion and increased $\mathrm{Hb}$; plasma heme and HPX are not included. Recent longitudinal studies in patients provide insight into diverse conditions where a high hemolytic index rate, based principally on plasma $\mathrm{Hb}$, was due to the inability of $\mathrm{Hp} / \mathrm{CD} 163$ to function normally and clear $\mathrm{Hp}-\mathrm{Hb}$. Thus, in the presence of a high human immunodeficiency virus (HIV) load (Delanghe et al., 2010) HPX was depleted in a patient who presented with symptoms of severe sepsis or hemo-phagocytic syndrome. Blood, plasma, and urine were monitored periodically over 70 days to assess liver, kidney, and muscle function (Delanghe et al., 2010). Free Hb levels were $1.68 \mathrm{~g} / \mathrm{l}$ (normal $<0.11 \mathrm{~g} / \mathrm{L}$ ); Hp levels were $3.37 \mathrm{~g} / \mathrm{L}$ (reference values $0.3-2.0 \mathrm{~g} / \mathrm{L}$ ), and HPX was essentially undetectable (reference values $0.4-1.5 \mathrm{~g} / \mathrm{L}$ ). After admission, indicators of heme catabolism (i.e., total and direct bilirubin levels) were normal, but blood monocytes expressed slightly lower than normal CD163 levels. Plasma lactate dehydrogenase (LDH), an indicator of tissue damage, was elevated $\sim 10$-fold above normal. C-reactive protein was increased and serum creatinine was initially above normal. In the urine, $\mathrm{Hb}$ but not heme was detectable. High levels of $\mathrm{Hb}-\mathrm{Hp}$ complexes were detected in the plasma by starch gel electrophoresis followed by staining for heme (from its peroxidase activity). The circulating $\mathrm{Hb}-\mathrm{Hp}$ levels declined as the viral load decreased in response to antiviral therapy, as did C-reactive protein and creatinine, indicating less oxidative stress. The HIV particles likely competed for $\mathrm{CD} 163$, limiting $\mathrm{Hp}-\mathrm{Hb}$ clearance. This patient presented with the Hp2-2 phenotype, shown to confer the worst prognosis of recovery from uncontrolled HIV (Delanghe et al., 1998; Delanghe and Langlois, 2002). The initial abnormally high Hp levels were considered to be due to hepatic induction in response to inflammatory mediators and since infection and inflammation affect monocyte/macrophage function. After an initial decline over the first 6 days they increased to within the normal range at day 16 and nearly doubled by day 70. HPX levels were very low initially $(0.1 \mathrm{mg} / \mathrm{ml})$, undetectable at day 6 but increased at day 16 to within the normal range $(0.8 \mathrm{mg} / \mathrm{ml})$ and slightly more by day $70(1.0 \mathrm{mg} / \mathrm{ml}$, Figure 1). Liver and kidney function improved as the viral load declined. These and other data (see Section
The Clearance of Hemoglobin by Hemopexin and Haptoglobin during Extravascular Hemolysis, below), demonstrate that key responses in the metabolism and regulation of HPX and Hp are needed to manage a heme load from $\mathrm{Hb}$. In this patient, HPX and $H p$ responded individually between day 6 and 16, thus providing an interesting time frame for future studies on plasma protein therapeutics.

Significantly, heme and iron and their binding proteins HPX and transferrin link nutritional immunity with the innate immune system. Also, CD163 links hemolysis and $\mathrm{Hb}$ clearance with the immune response because it acts as a pattern recognition receptor, which binds bacterial surface proteins (Fabriek et al., 2009), and an innate immune sensor for bacterial or local inflammation. Crosslinking of CD163 with antibodies or interaction with bacteria mediates release of pro-inflammatory cytokines (van den Heuvel et al., 1999; Polfliet et al., 2006; Fabriek et al., 2009). Whereas, binding of $\mathrm{Hb}-\mathrm{Hp} 1$ to CD163 directs the secretion of anti-inflammatory IL10 (Philippidis et al., 2004), although Hb-Hp-2 does not. CD163 induces a cascade of intracellular signals (Ritter et al., 2001) that involves tyrosine kinase-dependent calcium mobilization, inositol triphosphate production, and secretion of inflammatory IL6 and colony stimulating factor 1. Thus, CD163 functions, in an Hp-type dependent manner, to both activate and suppress the innate immune response.

$\mathrm{Hb}$ clearance from the plasma by $\mathrm{Hp}$ will depend principally upon the number of viable, functioning $\mathrm{CD}_{163}{ }^{+}$ monocytes/macrophages in the body. Hb removal was impaired in cells exposed to a drug conjugate of a monoclonal antibody drug compound, gemtuzumab oozogamicin, a biological drug used to treat acute myelogenous leukemia, which also lowers the number of $\mathrm{CD}_{163}{ }^{+}$cells (Maniecki et al., 2008). Perhaps consequently, this compound also increased vaso-occlusive disease in the absence of bone marrow transplantation (Giles et al., 2001). Gemtuzumab has now been withdrawn.

A high hemolysis index in the absence of hemolytic events occurred in response to the metabolism and heme clearance of the second generation Hb-based oxygen carrier blood substitute, pyridoxalated $\mathrm{Hb}$ polyoxethylene conjugate (PHP; Drieghe et al., 2013). Hb-based blood substitutes, under development for 40 years $^{2}$, are required for highway accident victims, battlefield casualties, transfusions when an immunological match is not possible or to replace transfused blood refused for religious reasons. Biochemically, they are needed to increase oxygen levels to tissues in the shift from hypoxia to more normoxic conditions in the capillary beds for endothelial cells and the underlying smooth muscle cells to restore their normal metabolism. This process is affected by blood flow rates as well as $\mathrm{Hb}$ levels and $\mathrm{O}_{2}$ unloading from $\mathrm{Hb}$. Patients respond to decreased $\mathrm{O}_{2}$ carrying capacity of blood by increasing cardiac output and ventilation with pulmonary vasodilation, and at the cellular level there is a shift to anaerobic glycolysis. ATP released from RBCs binds to ATP receptors on endothelial cells and induces nitric oxide

\footnotetext{
${ }^{2}$ Workshop on artificial hemoglobin. http://www.fda.gov/downloads/ BiologicsBloodVaccines/NewsEvents/WorkshopsMeetingsConferences/Transcript sMinutes/UCM051545.pdf.
} 


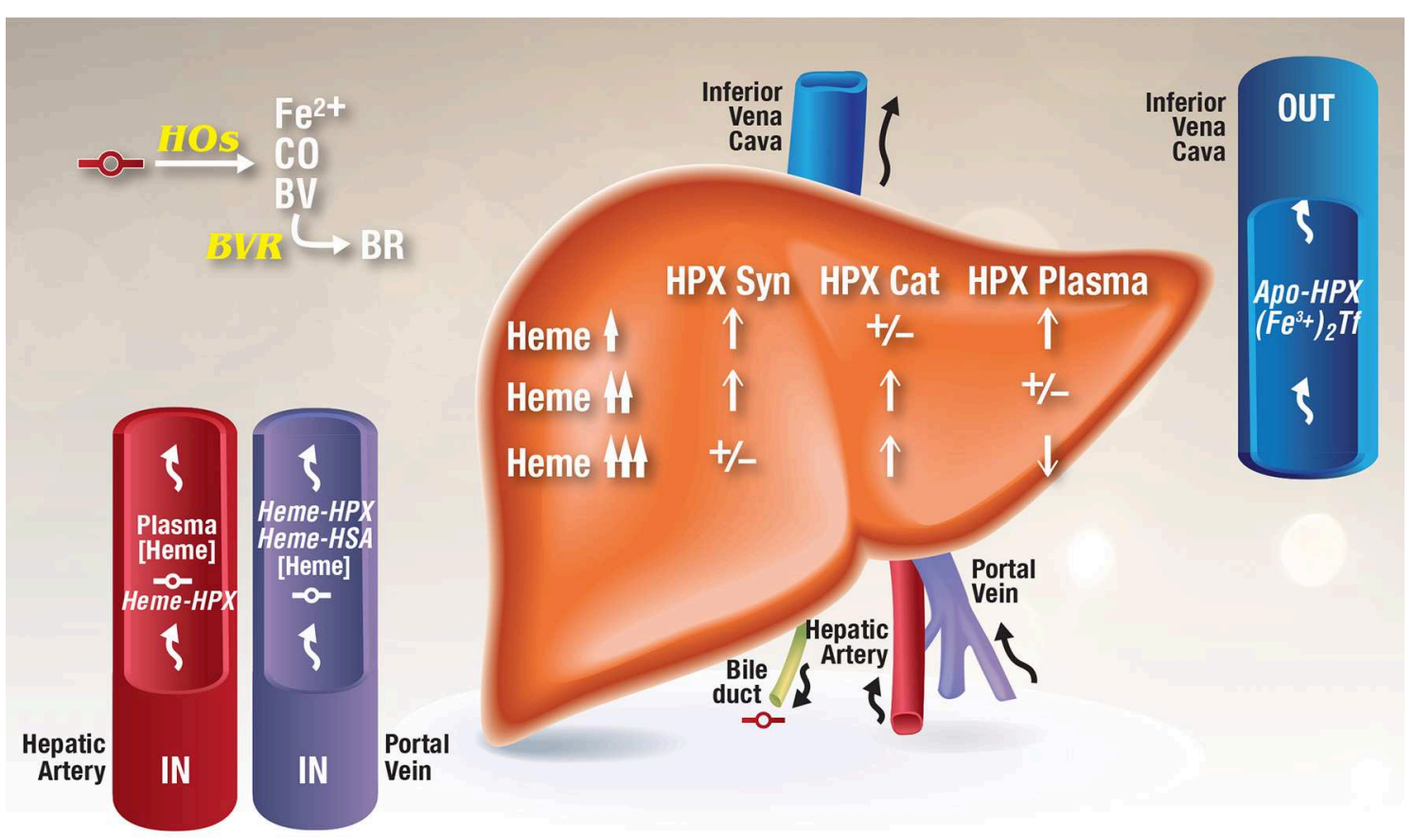

FIGURE 1 | Model for the development of HPX depletion states. This model is based on data from rhesus monkeys given heme i.v. (Foidart et al., 1982), HPX metabolism studies in humans (Foidart et al., 1983), known induction of HPX by heme (Smith, 1999; He et al., 2010), normal recycling of HPX after heme delivery (Smith and Morgan, 1978, 1979), and HPX catabolism after i.v. administration of heme several fold higher than the binding capacity of HPX (Sears, 1970; Lane et al., 1972). As heme-HPX forms in plasma, uptake of this complex by receptor-mediated endocytosis into liver parenchymal cells raises heme levels. In HPX deficiency states, heme will traffic unregulated into cells. HOs initially degrade this heme releasing redox active ferrous iron, $\mathrm{CO}$, and biliverdin, which is converted to bilirubin by cytosolic biliverdin reductase. Heme also travels to the nucleus to de-repress Bach 1 target genes including $\mathrm{HO}-1$ and also to induce other genes including the HPX gene. As intracellular levels of heme rise in liver cells in response to increases in plasma heme, changes in HPX synthesis and catabolism are reflected in plasma HPX levels as indicated. Heme is a normal component of bile and as hemolysis progresses, unregulated heme diffusion into cells raises heme levels such that any unmetabolized heme can potentially be exported into the bile (Petryka et al., 1977; McCormack et al., 1982). synthase. NO binding by $\mathrm{Hb}$ could cause vasoconstriction with a reduction in blood flow.

In an attempt to minimize the toxic effects of blood substitutes, $\mathrm{Hb}$ molecules have been designed to: survive for a long time in the circulation; bind $\mathrm{O}_{2}$; have a slow rate of heme autoxidation and scavenge NO minimally. Nevertheless, many blood substitutes are modified $\mathrm{Hb}$ molecules with low or no affinity for $\mathrm{Hp}$ compared with $\mathrm{Hb}$. $\mathrm{Hb}$ or heme released from them into the circulation or interstitial space is potentially toxic. PHP was designed to treat shock associated with the systemic inflammatory response syndrome (SIRS), which is an NOinduced shock with severe hypotension and vasoplegia disrupting major organ function leading to death. PHP has many antioxidant properties due to a covalent linkage to catalase and can scavenge $\mathrm{NO}$, and it does not readily oxidize either to metHb derivatives that do not bind $\mathrm{O}_{2}$ or to ferryl $\mathrm{Hb}$. It was anticipated to provide treatment in ischemia- reperfusion injury and hemorrhagic shock, where ROS such as superoxide and $\mathrm{H}_{2} \mathrm{O}_{2}$ and $\mathrm{NO}$ are known to be involved. Three patients treated with PHP $(0.25 \mathrm{ml} / \mathrm{kg} / \mathrm{h}$ for max of $150 \mathrm{~h} 3.5$ days 7 and 8 days peaks hemolysis index 350U, 650, and 900, respectively) were followed daily for 2 weeks. Plasma $\mathrm{Hp}$ levels remained normal but HPX was essentially undetectable by immune-nephelometry. Free $\mathrm{Hb}$ (measured as $\mathrm{PHP} \mathrm{Hb}$ with a higher molecular mass than $\mathrm{Hb}$ upon starch gel electrophoresis) was detected in the patients undergoing PHP infusions. The patient's Hp could bind $\mathrm{Hb}$ because $\mathrm{Hb}-\mathrm{Hp}$ complexes formed after $\mathrm{Hb}$ addition to plasma samples collected several days after the infusion occurred. Throughout this period, total bilirubin, and heme-binding serum $\alpha 1$-microglobulin levels were normal. Ongoing heme catabolism was apparent with total bilirubin levels increased for several days after PHP infusion. One patient had very low HPX levels initially that eventually rose to low normal levels as their elevated serum creatinine decreased slightly over the second week; and hepatic function improved too as the initially abnormally high aspartate transaminase and alanine amino transferases tended to decline in the second week. However, lactate dehydrogenase (LDH) levels were extremely high initially, increasing over days 3-10 then declining by days 12 and 14. In another patient whose HPX hardly responded, the $\mathrm{LDH}$ levels remained abnormally high. This group of patients provide an example of heme clearance by HPX with an increased hemolysis index value but with normal Hp.

HPX will be important in clearing myoglobin (Mb)-heme from injured muscle in crush injuries. $\mathrm{Mb}$ is expressed 
in cardiac myocyte and smooth muscle cells. Mb levels, normally $30-90 \mathrm{ng} / \mathrm{ml}$, increase 5- to 10 -fold $(\sim 500 \mathrm{ng} / \mathrm{ml})$ after myocardial infarcts (Almog et al., 1987; Sallach et al., 2004) and in neuromuscular disease (Foidart et al., 1983). In chronic neuromuscular conditions, heme from $\mathrm{Mb}$ affects hepatic HPX metabolism, as does heme and $\mathrm{Hb}$, in a dosedependent manner (see Section Heme Toxicity and Hemopexin Deficiency States and Refs. Foidart et al., 1982, 1983). In fulminant rhabdomyolosis, HPX is depleted and Mb levels are high, while $\mathrm{Hp}$ and $\mathrm{Hb}$ are normal implicating $\mathrm{HPX}$ in the clearance of circulating Mb (Adornato et al., 1978). Human Hp binds $\mathrm{Hb}$ in preference to $\mathrm{Mb}$ (Sakata et al., 1986). In Duchenne's muscular dystrophy and polymyositis where there is abnormal Mb metabolism HPX levels were high.

These patient studies justify adding heme and HPX levels to the hemolytic index (see Figure 1); and low HPX levels with elevated $\mathrm{LDH}$ may help to distinguish impaired heme plasma clearance from ongoing hemolysis (Drieghe et al., 2013).

\section{The Clearance of Hemoglobin by Hemopexin and Haptoglobin during Extravascular Hemolysis}

Mature RBCs will travel $\sim 300$ miles through the systemic vasculature during their 120 day lifespan enduring deformation at every twist, bifurcation, and turn, as well as exposure to changes in osmotic pressure when passing through the kidney and lung vasculature. This journey is equivalent in length to 11.5 marathon runs, and the RBCs may traverse the heart and its valves $\sim 1,70,000$ times. Extra-vascular hemolysis $(\mathrm{EVH})$ is the phagocytosis of senescent, damaged or otherwise abnormal RBCs by macrophages in the spleen, liver, bone marrow, and reticulo-endothelial system. Random hemolysis-or the age-independent destruction of RBCs occurs at a basal rate of $0.05-0.5 \%$ daily. Higher rates of random hemolysis can result in shorter $\mathrm{RBC}$ lifespan as does senescence. The chance of a RBC surviving 100 days is only $61 \%$ but only $1 \%$ survive 100 days when random hemolysis increases to $5 \%^{3}$. A compensatory increase in erythropoietin prevents anemia by increasing $\mathrm{RBC}$ production and $\mathrm{Hb}$ levels.

Most pathological hemolysis is $\mathrm{EVH}$ with the spleen playing a major role. EVH is stimulated after one or more blood transfusions in order to clear any RBCs that have deteriorated upon storage. In this case, EVH and IVH likely occur simultaneously, and, depending upon the quality of the stored blood and the number of transfusions, the hemolysis can expose cells and tissues to a significant amount of $\mathrm{Hb}$, heme, and iron. Transfusions can be extensive, for example, car accident victims may require 100 pints of blood, and there is the potential for a daily transfusion need during chemotherapy and a lifetime need in $\mathrm{SCD}^{4}$.

\footnotetext{
${ }^{3} \mathrm{http}: / /$ www.uptodate.com/contents/approach-to-the-diagnosis- of-hemolyticanemia-in-the-adult

${ }^{4}$ http://www.redcrossblood.org/learn-about-blood/blood-facts-and-statistics\# blood-components\$
}

After engulfment of RBCs by macrophages, the heme from $\mathrm{Hb}$ leaves the endosomes and reaches the smooth endoplasmic reticulum (ER) for catabolism by the HOs 1 and 2 (HO1 and HO2) where each heme molecule stoichiometrically releases redox active ferrous iron and carbon monoxide (CO). Heme also moves to the nucleus for gene regulation in part via depression of Bach1-regulated genes, including $\mathrm{HO} 1$ and $\operatorname{NADP}(\mathrm{H})$ :quinone oxido-reductase 1 (NQO1). These molecules protect cells against oxidative stress as levels of redox active heme and iron rise intra-cellularly. The iron from heme catabolism is either used for biochemical purposes including translational regulation, or is stored or exported via ferroportin (FPN1) and delivered to transferrin. Iron is delivered to liver parenchymal cells by transferrin or by macrophage-derived L-ferritin (Moss et al., 1992) from which it may be re-utilized for erythropoiesis depending upon the body's needs. The extent of iron export will be affected by any changes in surface FPN1 levels, including stabilization by the presence of multi-copper oxidases including ceruloplasmin (McCarthy and Kosman, 2014), loss due to proteasome degradation in response to circulating hepcidin (Nemeth et al., 2004) or increase as heme stimulates FPN1 transcription (Marro et al., 2010).

There is an important role for HPX in EVH after erythrophagocytosis to accept heme exported by FLVCR, a member of the major facilitator family of transporters thus preventing heme accumulation and toxicity (Smith, 2011a,b). Substrate solutes such as heme will diffuse down a concentration gradient in this type of transporter but heme export requires a plasma protein heme acceptor such as HPX or HSA (Yang et al., 2010). HPX then delivers heme to the liver (Smith and Morgan, 1978, 1979). Erythrophagocytosis induces HO1 and it is established that heme degradation by HOs is protective against heme toxicity in essentially all cell types with ferritin synthesis and effective heme and iron export. Phagocytic activity is "safe" for macrophages when they engulf $<1.5$ RBCs. Subsequently, $40 \%$ of the $\mathrm{Hb}$-iron is released in vitro within $24 \mathrm{~h}$. Ingestion of too many RBCs is lethal in part due to iron toxicity (Kondo et al., 1988). However, in vitro experiments with macrophage are not carried out in the presence of in vivo levels of HPX, HSA or transferrin.

Evidence supports that heme toxicity in macrophages after erythro-phagocytosis develops either when plasma HPX levels are low, presumably with concomitant IVH, or if $\mathrm{HO} 1$ activity is compromised. Both scenarios would contribute to raising intracellular heme levels in macrophages (and also in hemeexposed endothelial cells). The catalytic capacity of HOs may become overwhelmed by the amount of intracellular heme or when there are insufficient substrates and coenzymes for catalytic activity $\left(\mathrm{O}_{2}\right.$ and $\mathrm{NADPH}$ for the obligatory $\mathrm{HO}$ reductase, cytochrome $\mathrm{P}-450$ reductase). Lowering elevated intracellular heme via FLVCR-mediated export to HPX is another solution. However, this route would be compromised when circulating HPX is low or absent; and exacerbated when the hydrophobic drug binding site in HSA (Ghuman et al., 2005) that accommodates heme is occupied by medications. In these circumstances, $\alpha_{1}$-microglobulin may provide additional sites for heme. 
In humans, a relationship between HO1 activity and HPX metabolism was first apparent in HO1-deficiency with undetectable HPX levels in a child that succumbed by 6 years (Yachie et al., 1999), as previously reviewed (Smith, 2011b, 2013); and which is recapitulated in part, in $\mathrm{HO}^{-/-}$mice that also have low HPX (Kovtunovych et al., 2010). In both situations, the key role for macrophage HO1 activity for heme catabolism and subsequent safe iron distribution in the body with minimal inflammation is apparent. Also, extensive LDL oxidation was detected in this patient perhaps from oxidation of cell free Hb (Jeney et al., 2002) and exacerbated by the HPX deficiency. Both HO1-deficient mice and humans are anemic and in the limited number of humans with HO1 deficiency hyposplenia was found (Yachie et al., 1999), although mice develop splenomegaly from progressive changes in the spleen as macrophages become depleted and heme toxicity develops. As murine $\mathrm{HO}^{-/-}$macrophages undergo erythrophagocytosis, they burst releasing their contents, including presumably heme, into the spleen causing fibrosis in the areas of red pulp. IVH occurs as senescent $\mathrm{RBCs}$ release $\mathrm{Hb}$ and heme. The few remaining $\mathrm{CD} 63^{+}$macrophages in the spleen cannot effectively clear the $\mathrm{Hp}-\mathrm{Hb}$ complexes as they do normally. The hepatic parenchymal cells and kidney proximal tubules are thought to become new iron storage sites instead of liver and spleen macrophages. A HPX deficiency state develops in $60 \%$ of 8 months old $\mathrm{HO}^{-/-}$mice, while both $\mathrm{Hp}$ and HPX mRNA are increased in the liver. HPX mRNA increases in the liver lysates of $\mathrm{HO}^{-/-}$mice even by 7 weeks of age and HPX mRNA was also detected at extra-hepatic sites, e.g., in the spleen and kidney, likely due to induction by heme (Smith, 1999) or perhaps the inflammatory cytokine, IL-6 (Tolosano et al., 1996). Although, low plasma HPX and high hepatic HPX mRNA may appear discordant (Vinchi et al., 2008; Kovtunovych et al., 2010), the $\mathrm{HO}^{-/-}$mice likely have high hepatic heme levels; in which case there is no anomaly because high levels of hepatic heme increase HPX catabolism without compensatory HPX synthesis by the liver as shown in humans with hemolytic anemia and in rhesus monkeys (see Section Heme Toxicity and Hemopexin Deficiency States). Bone marrow transplantation successfully replenished normal progenitors of macrophages restoring Kupffer cell activity to the $\mathrm{HO}^{-/-}$mouse liver (Kovtunovych et al., 2014) and demonstrating a potential therapeutic strategy.

Successive blood transfusions expose endothelial cells to large amounts of $\mathrm{Hb}$ and heme with IVH occurring simultaneously with $\mathrm{EVH}$, especially in the initial stages of each transfusion. CD163-mediated endocytosis of $\mathrm{Hp}-\mathrm{Hb}$ in macrophages requires ATP. How erythro-phagocytosis affects the overall metabolism of macrophages and how long the cells need to recover the membrane components including CD163 at their cell surface is not known in detail. Presumably, significant amounts of energy are utilized and components of the surface membranes such as lipids and proteins including CD163 may be catabolized or redistributed in the cell. Thus, erythrophagocytosis may decrease CD163 surface expression with deleterious consequences for the endocytosis and uptake of $\mathrm{Hp}-\mathrm{Hb}$ or possibly other CD163 ligands including $\mathrm{Hb}$ in various hemolytic conditions. Under these circumstances, high levels of metHb are expected and protection against heme toxicity by HPX will become significant until there is sufficient replenishment of $\mathrm{CD}_{163}{ }^{+}$ mature macrophages. That this is the case in the clinic is suggested by data obtained during cardiopulmonary bypass (CPB) that entails extracorporeal blood circulation, including priming of the circuit with stored blood and potentially also blood transfusions. Patients with compromised liver function, especially liver cirrhosis and a history of alcohol abuse will not readily synthesize HPX (Vladutiu and Kim, 1981), transferrin and $\mathrm{Hp}$-all extracellular anti-oxidants against heme and iron.

Pediatric patients are especially at risk during CPB due to their lower endogenous HPX levels and need to avoid iron loading, which can lead to problems in neurodevelopment later in life, including decreased IQ, motor deficiencies, impaired language skills, and a higher incidence of behavioral and attention problems (Lull et al., 2008). In neonates especially, surgeryrelated pathology can occur even with great precautions and improved technology. HPX levels were analyzed by immunoblot in plasma samples taken just before $\mathrm{CPB}, 5$ min into $\mathrm{CPB}$, at the end of $\mathrm{CPB}$ and then 1 and $24 \mathrm{~h}$ post-CPB. In $5 / 13$ proteins that changed, HPX and the serine protease inter- $\alpha$-inhibitor 4 decreased; furthermore copper and $\mathrm{Hb}$ levels increased while iron decreased. Although on a non-linear timescale, HPX levels dropped $60 \%$ at initiation of $\mathrm{CPB}$ and remained low until the end of $\mathrm{CPB}$, then increased to about $75 \%$ of the initial value. Hb levels increased from 20 to $60 \mathrm{mg} / \mathrm{dL}$ during $\mathrm{CPB}$, and had returned to normal by $24 \mathrm{~h}$ post $\mathrm{CPB}$. No changes in $\mathrm{Hp}$ were reported in this study. This rapid, dramatic decrease in HPX levels suggests that the primed blood had generated significant levels of heme to deplete circulating HPX levels and that the heme-HPX complex left the circulation via the liver.

\section{Studies on Patients with Hemolytic Diseases Reveal Complex Relationships between Hemopexin and Haptoglobin Levels}

Heme sequestration by HPX, its extracellular anti-oxidant function, directly protects cells against heme toxicity; furthermore, heme transported to the liver affects HPX metabolism (see Section Improving Animal Models of Human Disease in which Hemopexin and Haptoglobin Play a Protective Role). Thus, pinpointing when plasma heme levels rise and the response of HPX will aid in the diagnosis, development of targeted plasma therapeutics, and patient treatment. Plasma HPX levels were first proposed in 1975 to reveal the severity of hemolysis (Muller-Eberhard and Liem, 1975) when grafted heart valves malfunction. HPX infusion therapy for patients with myocardial infarcts was first proposed in 1993 (Muller-Eberhard and Fraig, 1993). It was noted that this would be simpler technically than measuring $\mathrm{CO}$ exhalation, the number of deformed RBCs (schistocytes), serum LDH and urine hemosiderin excretion or the half-life of radioactive RBCs as indications of the extent of hemolysis. Also, plasma $\mathrm{Hb}$ levels are compromised by hemolysis during blood collection and storage unless special care is taken. 
The clinical units for plasma proteins are in $\mathrm{mg} / 100 \mathrm{ml}$; whereas, molar units and stoichiometry reveal ligand clearance by transport proteins. One molecule of HPX binds one molecule of heme (Drabkin, 1971); based on an average adult HPX plasma level of $770 \mu \mathrm{g} / \mathrm{ml}, \sim 6.3 \mu \mathrm{g}$ heme would be bound per ml plasma and higher heme levels would deplete HPX unless recycling takes place or rapid compensatory synthesis takes place (MullerEberhard et al., 1968). In molar terms and based on heme binding by HPX in mammalian sera, the HPX levels are $\sim 12.44 \mu \mathrm{M}$ $($ Drabkin, 1971$)=1.8 \times 10^{19}$ molecules in $2.23 \mathrm{~L}$ av. plasma volume based on $55 \%$ of $4.7 \mathrm{~L}$ blood volume ${ }^{5}$. Normal plasma heme rarely exceed $5 \mathrm{mg} / 100 \mathrm{ml}$ plasma $(\sim 78 \mu \mathrm{M})$ using a modification of the benzidine method. At $>10 \mathrm{mg}$ heme $/ 100 \mathrm{ml}$, methemalbumin accounted for $\sim 65 \%$ of the plasma heme and HPX was often decreased in such plasma. Patient samples often had $>20 \mathrm{mg}$ heme $/ 100 \mathrm{ml}$ and $325 \mathrm{mg} / 100 \mathrm{ml}$ has been measured in malaria (Sears, 1968). It is generally accepted that plasma Hp is depleted when plasma $\mathrm{Hb}$ is $>50-200 \mathrm{mg} / 100 \mathrm{ml}$. $\mathrm{Hb}$ then passes through the kidney glomeruli and some is retained by the proximal tubular cells where the heme-iron is converted to hemosiderin (detected as urinary iron). Tubular cells are later shed into the urine producing hemosiderinuria and unabsorbed $\mathrm{Hb}$ is excreted in the urine (hemoglobinuria). Notably, plasma schistocyte count and urinary hemosiderin, a measure of excess RBC destruction, correlate inversely with HPX levels (Eyster et al., 1972).

In the early 1960's and early 1970's, the groundwork for our understanding of the changes in plasma HPX levels in response to increased plasma heme during the course of hemolytic events and human inherited hemolytic diseases was laid by MullerEberhard's group with additional longitudinal patient studies by Sears. Although the patient number is relatively small in these studies, key facts about HPX function and metabolism are apparent. Both groups provided evidence for a complex, nonlinear but significant, relationship between plasma HPX and heme levels (but not $\mathrm{Hb}$ ); whereas $\mathrm{Hp}$ levels were related to $\mathrm{Hb}$ levels not heme (Muller-Eberhard et al., 1968; Sears, 1968); see also Section Heme Toxicity and Hemopexin Deficiency States). HPX catabolism did not require Hp depletion; thus, Hp and HPX often simultaneously protect against the development of heme toxicity from $\mathrm{Hb}$. As previously reviewed (Smith, 2011b), comparison of the extent of exogenous heme clearance with HPX levels supported that HPX recycles after heme delivery to the liver (Muller-Eberhard et al., 1968; Drabkin, 1971), which was subsequently shown directly using radioactive heme- ${ }^{125}$ I-HPX in rats (Smith and Morgan, 1978, 1979) and confirmed in human hepatoma cells (Smith and Hunt, 1990). These findings remain particularly relevant for and important in the development of plasma protein therapeutics with HPX and/or Hp.

In many inherited hemolytic diseases, episodes of heme toxicity occur in a background of chronic oxidative stress and inflammation, as in mice models of SCD (see Section Key Roles for Heme Toxicity in the Pathogenesis of Sickle Cell Disease and Protection by HPX). Sepsis can also entail prominent episodes of hemolysis that are ameliorated by HPX supplementation (see

$\overline{{ }^{5} \mathrm{http} / / / \text { anthro.palomar.edu/blood/blood_components.htm }}$
Section Key Roles for Heme Toxicity in the Pathogenesis of Sepsis and Protection by Hemopexin). Assessment of the association of HPX levels with the presence of specific diseases, response to therapies, and prognostication of clinical outcomes requires longitudinal studies. These involve repeated monitoring of risk factors and/or outcomes, often on a daily basis. Ideally, the controls will possess similar baseline characteristics as cases, with the primary differences being only the exposure of interest. Both HPX and Hp levels can change quickly in response to a hemolytic episode that "resolves" generally within 1-2 weeks. To a certain degree, the early research on HPX and Hp provides a unique window on the unfolding events affecting the metabolism of these proteins during and after hemolysis-and in the presence and absence of infection. The circulating plasma levels of $\mathrm{Hp}$, HPX, and HSA vary quite widely within the normal population, but are stable for a healthy individual. Cohort studies that use data from much larger groups of patients, which share common characteristics and exposures, are the backbone of current proteomics and outcomes research. Large group cohort studies can be carried out prospectively or retrospectively with differing exposures to a suspected factor or treatment; and then observed and tested generally. Given the relatively rapid changes in HPX and Hp levels, frequent sampling may be necessary to identify correlations between changes in HPX and Hp metabolism and a patient's clinical status.

Decreased plasma HPX levels in hereditary hemolytic diseases was first reported in a study of 38 children in 1963 (MullerEberhard and Cleve, 1963). Haptoglobinemia, defined by a lack of detectable $\mathrm{Hb}$ binding in plasma, was found in spherocytic anemia with HPX deficiency in $50 \%$ of the children before splenectomy to reduce hemolysis; after which $\mathrm{Hp}$ was restored in $50 \%$ of the children and HPX in all of them. Hp was undetectable in $50 \%$ thalassemia major subjects but increased in $100 \%$ after splenectomy, whereas HPX only increased in one patient. HPX levels in thalassemia minor were apparently normal, which may reflect the lower levels of heme circulating in that condition. In children with SCD, Hp was low in all cases and HPX was found to be decreased in all but one subject. A later report showed that both HPX and Hp are depleted in sickle cell anemia, sickle cell-HbC disease or thalassemia major (Muller-Eberhard et al., 1968). HPX and Hp were depleted simultaneously in two patients with severe hemolytic reactions to blood transfusions, one linked to anti-E antibodies. There are even cases where HPX levels are normal although $\mathrm{Hp}$ has disappeared from the plasma (see also Section Structure and Function of Hemopexin and Haptoglobin and their Role in Heme and Hemoglobin Clearance in Intravascular Hemolysis).

Some early longitudinal studies revealed that HPX levels were restored to normal far more quickly than Hp levels after a hemolytic episode from a variety of causes (Sears, 1968). After each acute episode, heme levels generally spiked $(\sim 325 \mathrm{mg}$ heme $/ 100 \mathrm{ml}$ for example in malaria) within $24 \mathrm{~h}$ decreasing to normal after 6 days and HPX levels start to increase within $24-48 \mathrm{~h}$. However, Hp remained low requiring 14 days to return to normal plasma levels. This was attributed to a slow ongoing destruction of RBCs and/or the absence of one or more sufficient stimuli for de novo Hp synthesis. As described in Section The 
Clinical Relevance of Hemoglobin, Hemopexin, and Haptoglobin Levels, macrophage clearance of RBCs is vital for heme and iron homeostasis as it minimizes oxidative stress and inflammation from heme toxicity (Kovtunovych et al., 2010). We propose that severe acute or chronic HO1 impairment links decreased macrophage function in presence of EVH and/or IVH eventually depleting HPX. However, in relapse from falciparum malaria and in renal insufficiency associated with an immediate hemolytic reaction to a blood transfusion (Sears, 1968), HPX and Hp were depleted and both rapidly restored to normal essentially immediately after plasma heme levels declined.

Without obvious changes in HPX levels, Hp became depleted following hemolysis in response to primaquine in erythrocytic glucose 6-phosphate dehydrogenase deficiency and in relapsed pernicious anemia (Sears, 1968). In the latter case, 10 days after vitamin B12 therapy, Hp levels began to increase. Intriguingly, when the patient developed an infection (pharyngitis, fever and strep throat) there was a rapid and marked two-fold increase in Hp levels within 2-4 days without significant changes in HPX plasma levels, demonstrating that it is not an acute phase protein in humans (Kushner et al., 1972). Such changes would likely not be apparent in patient proteomic studies where large numbers of control and disease groups are compared.

A HPX deficiency with normal Hp levels $(76 \mathrm{mg} / 100 \mathrm{ml})$ was seen in hemorrhagic pancreatitis, where plasma heme was high at $47 \mathrm{mg} / 100 \mathrm{ml}$ (Sears, 1968). Acute hemorrhagic pancreatitis is an acute inflammation of the pancreas frequently accompanied by hemorrhages into the gland itself and into the parenchyma and surrounding tissue. This condition is often fatal due to the development of shock and multi-organ dysfunction/failure, particularly the lungs and liver, as well as the development of disseminated IVH coagulation. The causes generally include bile duct obstruction (in $50 \%$ of all cases), and toxicity from glucocorticoids, acetaminophen, and thiazide diuretics (Frey, 1979).

Normal or only slightly decreased HPX levels with low Hp were detected in paroxysmal nocturnal hemoglobinuria and in auto-immune hemolytic anemia (AHA, Muller-Eberhard et al., 1968). In AHA patients, $\mathrm{Hp}$ was below the normal levels of $140 \mu \mathrm{g} / \mathrm{ml}$, reticulocyte counts were high (23-70\%; normal levels are $0.5-1.5 \%$ ) and antibodies to RBCs were present as shown by positive direct and indirect Coombs test reaction. The reticulocyte count indicates how fast RBC precursors, reticulocytes, are made in the bone marrow and released into the blood stream. This is a normal response to blood loss or premature destruction of RBCs as in hemolytic anemias, which would also be reflected by low blood Hb levels. Kidney disease with increased erythropoietin levels will also increase reticulocyte count.

Normal HPX levels with low Hp was also detected in an adult patient with hereditary spherocytosis, which is the most common form of inherited anemia in individuals of Northern European descent. Mild or severe anemia is due to genetic defects in proteins including ankyrin (ANK1 gene) needed for normal flexibility of red blood cell membrane. These misshapen cells are recognized and taken up by the spleen and destroyed, often necessitating multiple blood transfusions. HPX levels were found to be normal $(400 \mu \mathrm{g} / \mathrm{ml})$ and $\mathrm{Hp}$ was low but rose $~ 5$ fold to $600 \mu \mathrm{g} / \mathrm{ml}$ after splenectomy (Muller-Eberhard et al., 1968).

Overall, these and other clinical studies (Section The Clinical Relevance of Hemoglobin, Hemopexin, and Haptoglobin Levels) demonstrate a need to examine the often stated concept, originating from the late 1960's, that HPX is depleted only when $\mathrm{Hp}$ is absent (Gladwin and Ofori-Acquah, 2014). HPX levels decline when a substantial amount of heme is present in plasma because as hepatic heme increases, HPX catabolism exceeds de novo synthesis in humans and rhesus monkeys (see Section Improving Animal Models of Human Disease in which Hemopexin and Haptoglobin Play a Protective Role). Thus, to further define the stages and cause of hemolysis and particularly to distinguish impairment of heme clearance from hemolysis, knowledge of plasma heme and HPX levels would enhance the ability of clinicians to define the clinical ramifications.

\section{The Hemopexin System Links Heme and Iron Metabolism}

Evidence for this link comes from different experimental approaches in humans and animals. Heme-iron recycling was linked to HPX and heme clearance, by following i.v. ${ }^{59} \mathrm{Fe}$-hematin (0.77-1.23 mg heme/kg body wt.) in IVH from mechanical damage due to aortic and mitral prostheses; IVH from paroxysmal nocturnal hemoglobinemia due to complement destruction of RBCs; and HPX depletion (in the author) after five injections of hematin i.v. (Sears, 1970). Heme bound to HPX and HSA immediately but transfers within $3 \mathrm{~min}$ in vivo to HPX (Muller-Eberhard et al., 1969; Drabkin, 1971). Body surface counting showed, as expected, most radioactivity in the liver rising over 1-2 days and in the spleen increasing over the first $24 \mathrm{~h}(\sim 20 \%$ dose $)$ before reaching a plateau that was maintained for 21 days. Counts rose over the sacrum within this time supporting rapid re-utilization and ${ }^{59} \mathrm{Fe}$ was rapidly detected in the RBCs. There were no changes in plasma HPX, Hp, or bilirubin; and no detected in the urine. In normal subjects, the heme-iron was incorporated into circulating RBCs within $48 \mathrm{~h}$, reached $20 \%$ dose in about a days, 37\% dose in 3 weeks and 50\% dose over 8-12 weeks. This was noted as slightly slower than for Hb-iron re-utilization (Garby and Noyes, 1959) or Hb-iron from effete RBCs (Noyes et al., 1960). Iron status affected hemeiron re-utilization and more than $60 \%$ dose after HPX depletion and $\sim 70 \%$ in the subject with mechanical hemolysis at 21 days. A detailed analysis was confounded in patients with iron overload due to dilution of the radioisotope by iron stores.

As described previously (Smith, 2011b, 2013), iron status affects the HPX system: the surface receptors for heme-HPX and heme uptake are increased in iron deficiency, and decreased in iron overload (Smith and Ledford, 1988). HPX delivers heme to cells where it is broken down by HOs and the iron released. The heme-iron is stored on ferritin (Davies et al., 1979), or used for metabolic purposes including an iron source for cell growth for which an iron-enzyme ribonucleotide reductase is needed (Smith and Ledford, 1988) or for regulation via the IRP/IRE system of 
proteins of iron homeostasis in human retinal pigment (Hunt et al., 1996) and human neuroblastoma cells (Hahl et al., 2013).

Oligodendrocytes are the predominant iron-containing cells in the brain, often clustered around a blood vessel, and provide support for CNS neurons. Their only known function is myelin production where iron is a required as a co-factor for cholesterol and lipid biosynthesis, and for oxidative metabolism, which occurs at a higher rate in oligodendrocytes than other types of brain cells (Connor and Menzies, 1996). HPX is proposed to act in the maturation of oligodendrocytes. As $\mathrm{HPX}^{-/-}$mice age, there are fewer mature OLs and more precursor cells although brain iron accumulates. The density of myelinated fibers in the basal ganglia and in the motor and somatosensory cortex of $\mathrm{HPX}^{-/-}$mice decreased at 2 months (equivalent to a young human adult), with decreased neuromotor function (Morello et al., 2011).

\section{Heme Toxicity and Hemopexin Deficiency States}

\section{Coordination of Extracellular and Intracellular Defenses May Be Needed under Specific Circumstances to Survive Heme Toxicity}

Oxygen radical reactions occur upon tissue damage and heme with its redox active iron participates in such reactions that can lead to the degradation of proteins, lipids and carbohydrates and nucleotides (DNA and, likely, also RNA). Cells rely on the proteins in extracellular fluids to limit such radical chemistry by converting pro-oxidant forms of iron to less reactive forms (Halliwell and Gutteridge, 1990). HPX is one of these extracellular anti-oxidants as are $\mathrm{Hp}$, transferrin and ceruloplasmin. Only HPX, not Hp, inhibited hemin-stimulated lipid peroxidation providing direct evidence for HPX as the primary extracellular antioxidant protector against heme toxicity in biological fluids (Gutteridge and Smith, 1988). There are numerous examples of this: HPX prevents heme uptake into the aorta (Bui et al., 2004) and endothelial cells while targeting heme to the liver (Smith and Morgan, 1979).

In addition to IVH and EVH, sources of heme in vivo would include rupture of atherosclerotic plaques and trivial hemolysis in areas of turbulent blood flow such as the bifurcations of major blood vessels may create areas of sensitized endothelial cells. Heme $(1-7 \mu \mathrm{M})$ sensitized porcine aortic endothelial cells in vitro to subsequent oxidative stress leading to cell death (Balla et al., 1991b). Either a bolus of $\mathrm{H}_{2} \mathrm{O}_{2}$; gradual levels of $\mathrm{H}_{2} \mathrm{O}_{2}$ generated enzymatically by xanthine and xanthine oxidase or ROS produced by phorbol ester activated neutrophils (human polymorphonuclear cells) were toxic. When heme was bound by HPX (i.e., presented as a 1:1 stoichiometric mixture of heme and HPX) there was no endothelial cell toxicity (Balla et al., 1993), as expected because endothelial cells lack of HPX receptors (Smith and Morgan, 1979). Protection against heme toxicity was also conferred by catalase but not by SOD supporting that $\mathrm{H}_{2} \mathrm{O}_{2}$ is the ROS. If cells were incubated with ROS before $\mathrm{HO} 1$ and ferritin were induced by heme, the endogenous levels were not effective protection. If ROS exposure occurred a few hours after heme, both proteins confer protection due to their induction by heme and iron, respectively. Several other inducers associated with the inflammatory response and hypoxia are also good inducers of $\mathrm{HO} 1$ but not necessarily ferritin protein levels. Some ideal of the temporal relationship is provided by studies albeit in a different cell type. Maximum HO1 protein levels ( $\sim 2$-fold) are induced in mouse hepatoma cells within 3-6 h exposure to hemeHPX, whereas the iron released from heme catabolism may not induce ferritin via translation until $\sim 7-11 \mathrm{~h}$ (Alam and Smith, 1989; Sung et al., 2000). Endothelial cell death was accompanied by increased membrane lipid peroxidation. Endothelial cells are in danger in inflammation with activated neutrophils in close proximity that marginate along endothelial surfaces in presence of diverse inflammatory mediators.

\section{Key Roles for Heme Toxicity in the Pathogenesis of Sickle Cell Disease and Protection by Hemopexin}

There has been evidence, some published over 35 years ago, that a lack of plasma HPX, or the presence of heme-HPX with methemalbumin, is an ominous prognosis in sepsis (Larsen et al., 2010; Jung et al., 2015), as well as hemorrhagic shock (FriedmanMor et al., 1978) and liver cirrhosis (Vladutiu and Kim, 1981). SCD is a really important common disease entity and there is experimental evidence from in vitro studies with human and rodent cells as well as SCD mice that heme released from metHb is a major cause of several pathological symptoms, which are prevented by HPX in vitro and in vivo. Plasma heme rises in SCD patients from 0.2 to $\sim 4 \mu \mathrm{M}$ and may exceed $20 \mu \mathrm{M}$ (see references in Belcher et al., 2014). Thus, HPX protects by acting as an extracellular anti-oxidant sequestering the heme and targeting the heme-HPX complexes to cells that play a role in iron homeostasis, particularly the liver (Smith and Morgan, 1979). HPX deficiency develops in SCD, in $\beta$-thalassemias and in mice models of SCD. Several avenues of how this damage is mediated and how it can be ameliorated have been opened up recently including the modulation by HPX of the inflammatory immune response activated by heme.

In SCD, genetic mutations in globin, generate unstable molecules, HbS, that cause distortions in red blood cell structure, thus increasing their fragility such that shear forces in blood vessel forks and capillary bed cause lysis. The ensuing hemolysis leads to a constant damaging oxidative stress due partly to the chemical reactions that hemoglobin and heme undergo as HPX and Hp levels decline. Painful episodes, or "crises," are thought to be due to events that precipitate vaso-occlusion in the presence of chronic hemolytic anemia and also an even more rapid hemolysis termed "hyperhemolysis." Heme drives endothelial cell expression of adhesion molecules to which platelets and RBCs attach, ultimately blocking blood flow. Systemic inflammation occurs simultaneously with ROS release, and, together with ischemia reperfusion injury, which may lead to cerebrovascular compromise (strokes) and organ infarction. The only cure for SCD is bone marrow transplantation, which carries significant risks of morbidity and mortality due to immune suppression or injury induced by the donor immune system recognizing recipient antigens as foreign (graft vs. host disease). 
Other patient treatments include approaches to avoid vasoocclusion crises, palliative therapy to manage pain and to relieve symptoms, and antibiotic prophylaxis to prevent infections and pneumonia. New treatments include gene therapy to produce normal $\mathrm{Hb}$, drugs to produce fetal $\mathrm{Hb}$ (which lack the abnormal beta subunits that cause hemoglobin polymerization and RBC sickling), NO therapy to prevent sickle cell clumping and statins to limit cholesterol levels and decrease oxidative stress in blood vessels ${ }^{6}$.

HPX deficiency in SCD mice promotes vaso-occlusion (Belcher et al., 2014) and lung injury, i.e., acute chest syndrome (Ghosh et al., 2013). The extent of any hemolysis is driven by $R B C$ instability and the extent of potential heme toxicity by changes in heme that affect it's binding to globin. Compared with $\mathrm{HbAA}$ mice, the RBCs in HbSS mice turn over rapidly ( $t_{1 / 2}$ of $2-5$ days) in a steady state of stasis at $\sim 8-10 \%$. Infusions of $\mathrm{Hb}$ in the HbSS mice increased stasis to $30 \%$. Co-administration of either $H p$ or HPX with Hb prevented stasis, supporting that heme is the active agent. HbS caused more stasis than $\mathrm{HbA}$ consistent with its known instability and supporting that $\mathrm{HbS}$ more readily releases heme; thus, enhancing the pathology of SCD. Infusions of $\mathrm{HbA}$ into control mice generated low levels of stasis (similar to saline-induced iv hemolysis). Thus, heme induces stasis in sickle, not WT, mice. As platelets and RBCs adhere to the walls of endothelial cells lining blood vessels, the blood flow slows and vaso-occlusion can occur. Heme must be released from met $\mathrm{HbA}$ to cause the pathology because the stable derivative of heme, cyanometHb, did not cause vaso-occlusion (36.2\% stasis vs. $8.2 \%$, respectively); nor did mixtures of $\mathrm{HbA}$ with methylene blue (ferro-Hb), or HbA with $\mathrm{Hp}$, or HbA with HPX.

HPX is part of the innate immunity defense and TLRs are part of the innate immune system to restrict pathogen growth. Heme activates TLR4 leading to TNF $\alpha$ production in mice macrophages in vitro (Figueiredo et al., 2007). Using TAK-242 to block the TLR4 interaction with its adaptor molecule, and with TLR4 ${ }^{-/-}$cells and mice, TLR4 was shown to be needed for the heme-responsive trafficking of adhesion molecules to the surface of endothelial cells (Belcher et al., 2014). Importantly, this pathway and a role for TLR4 has also been validated in human endothelial cells. HPX prevented the rapid migration of P-selectin and Von Willibrand Factor (VWF) to the cell surface in response to heme. HPX also prevented heme stimulation of Weibel-Palade body degranulation and the increase in surface P-Selectin and VWR after $24 \mathrm{~h}$ incubation with either $\mathrm{HbS}$ or $\mathrm{HbA}$. This response was related to the amount of heme because the surface expression of P-Selectin and VWF was greater in response to $\mathrm{HbS}$ compared with $\mathrm{HbA}$, reflecting the faster rate of heme loss from HbS (Hebbel et al., 1988). Inhibitors of PKC and NADPH-oxidase or inhibition by anti-oxidants such as $\mathrm{N}$-acetyl cysteine and iron chelators provided presumptive evidence for the involvement of ROS and oxidative stress as part of heme-induced WPB degranulation in endothelial cells and consequent stasis. The $\mathrm{NF}_{\mathrm{K}} \mathrm{B}$ signaling pathway was also needed in part. Adhesion molecules identified to be involved

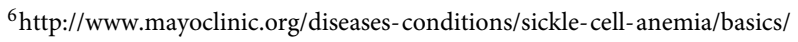
treatment/con-20019348. in heme-induced stasis in the sickle mice are VCAM1, $\alpha 4 \beta 1$ integrin, ICAM-1, PECAM-1, E-selectin, and $\alpha 4 \beta 3$ integrin. Unexpectedly, in mice, inactivation of one of these adhesion molecules at a time was sufficient to prevent stasis from taking place. Heme stimulation of surface adhesion molecule expression in cultured endothelial cells was recapitulated in NY1DD mice but not controls. P-selectin and VWF expression was detected on venules of the skin, brain, lungs, liver and kidney. The histochemistry showing EC activation and vaso-occlusion revealed clear differences in the different tissue capillary beds. Thus, tissue-specific responses of endothelial cells to: heme, heme and ROS, heme and inflammatory cytokine stimuli under either physiological or pathological conditions are expected. Belcher and colleagues (Belcher et al., 2014), pointed out that many local factors influence the different vascular beds e.g., EC heterogeneity, hemolysis, local cytokine milieux, HPX and $\mathrm{Hp}$ levels, $\mathrm{HO}$ activity, infections and oxygen gradients plus local or global changes in hemolytic rates, infection and hypoxia to trigger vaso-occlusive crisis. To show that hememediated stasis required TLR4 signaling in endothelial cells in vivo, chimeric NY1DD mice were generated that expressed HbS by transplanting bone marrow from NY1DD mice into irradiated $\mathrm{TLR}^{-/-}$and TLR $4^{+/+}$mice. Heme-induced stasis, using heme in the pathological range of $20-60 \mu \mathrm{M}$, occurred in the in the NY1DD $/ \beta^{s} /$ TLR $4+/+$ mice or non-transplanted NY1DD mice but not in the NY1DD/ $\beta^{\mathrm{s}} / \mathrm{TLR} 4^{-/-}$mice expressing $\mathrm{HbS}$. $\beta^{\mathrm{s}}$ expression is clearly needed for stasis because the heterozygous HbAS mice had levels of stasis that were intermediate between HbAA and HbSS mice.

Although, humans develop more severe lung injury than mice, heme caused lung injury in SCD mice via neutrophil extracellular trap (NET) formation, which was limited by HPX (Chen et al., 2014). NETS are thought to bind and eradicate pathogens but will also trap platelets and RBCs leading to vasoocclusion. Induction of NET formation in the lungs requires $\mathrm{TNF} \alpha$-activated neutrophils and can precipitate death. These neutrophils have higher levels of intracellular ROS and also generate ROS from myeloperoxidase, whose levels increase in the plasma. Decondensed chromatin is released that has granular enzymes such as elastase bound to it. The plasma of SCD patients has more activated neutrophils than non-sickle plasma, and in crisis contains significantly higher levels of DNA, nucleosome components, and myeloperoxidase. Heme levels were higher in the plasma of TNF- $\alpha$ treated SCD mice compared with controls. Furthermore, heme stimulated TNF- $\alpha$ primed neutrophils to generate NETs and, as with adhesion factor expression, this was related to heme concentration. Significantly, HPX reduced NET release by over $90 \%$ when cells were incubated with a mixture of equimolar amounts of heme and HPX. Heme-HSA, but not HbA, caused significant NET production, consistent with their relative affinities for heme. HPX infusion significantly lowered the heme concentration and reduced the number of pulmonary NETs, plasma DNA, nucleosome levels, and decreased MPO activity in SCD mice. Neither heme nor TNF- $\alpha$ alone caused detectable NETs release. Thus, these heme effects may occur in response to infection, which would in part explain the development of acute chest syndrome in SCD patients suffering from acute infections. 
Based on the known specificity and extremely high affinity of heme binding by HPX, the metHbA-induced stasis in a background of SCD oxidative stress was due to heme and HPX protects. Thus, in sterile inflammation with heme-TLR4 activation, heme has been proposed as an erythroid DamageAssociated Molecular Pattern molecule i.e., a DAMP (Gladwin and Ofori-Acquah, 2014).

\section{Key Roles for Heme Toxicity in the Pathogenesis of Sepsis and Protection by Hemopexin}

Sepsis is defined as SIRS due to identified or presumed infection and is the leading cause of death in the USA, affecting more than 1 million annually. Of these deaths, $28-50 \%$ are estimated to be due to multiple organ dysfunction syndrome ${ }^{7}$. Recovery from sepsis can be difficult and extended, and sepsis survivors may suffer prolonged or life-long disability. People with weakened immune systems, infants, and the elderly are most vulnerable to sepsis, as well as people with chronic illnesses including diabetes, HIV, cancer, and kidney or liver disease. It is reported that $70-90 \%$ of Ebola virus victims in West Africa in 2014 succumbed to sepsis with multi-organ failure ${ }^{8}$. This syndrome is the most expensive condition treated in US hospitals and cost $>\$ 20.1$ billion in $2011^{9}$. Unfortunately, sepsis remains a clinical diagnosis, due largely to the non-specific signs and symptoms that patients exhibit during the initial phase of illness. Earlier diagnosis and effective treatment of sepsis would save lives. Treatment of sepsis remains limited to supportive care (particularly vasopressive agents and intravenous fluids), rapid initiation of antibiotic therapy, and identification and drainage of sources of infection. Sepsis-specific treatments have been overall disappointing; however, evidence from mice supports that plasma protein therapies with HPX and /or Hp could be helpful in reducing the severity of illness and mortality.

Plasma protein therapies are established as plasma volume expanders after burns and in septic shock (HSA) and also infusions of immunoglobulins for certain immune deficiencies. Japanese and German physicians pioneered $\mathrm{Hp}$ infusions to prevent renal damage from hemoglobinuria in burns and, in 1977, the severe hemolytic damage accompanying ABO incompatibility (Homann et al., 1977). In CPB surgery (Tanaka et al., 1991), Hp was undetectable after 30-90 min and hemoglobinuria developed with renal tubular injury. When serum free $\mathrm{Hb}$ reached $>30 \mathrm{mg} / \mathrm{dL}$, $\mathrm{Hp}$ administration cleared plasma $\mathrm{Hb}$ within $30 \mathrm{~min}$, hemoglobinuria and improved kidney function. Hp infusions together with fluid resuscitation and plasma administration prevented post burn shock and acute renal failure in a young man with severe burn injury with lung damage (Imaizumi et al., 1994). Unfortunately, a second skin graft 51 days later led to death from sepsis with secondary cardiac failure. The $\mathrm{Hp}$ infusions used were: $2000 \mathrm{U}(2840 \mathrm{mg})$ for serum free $\mathrm{Hb} 50 \mathrm{mg} / \mathrm{dL}(1000 \mathrm{mg} / 50 \mathrm{~kg}$ body wt.) and $4000-8000$

\footnotetext{
${ }^{7}$ http://www.nigms.nih.gov/Education/Pages/factsheet_sepsis.aspx

${ }^{8} \mathrm{http} / / /$ world-sepsis-day.org/?MET=SHOWCONTAINER\&vCONTAINERID $=10$ 32.

${ }^{9} \mathrm{http} / / / \mathrm{www}$. infectioncontroltoday.com/news/2014/04/cdc-offers-new-sepsisfact-sheet.aspx.
}

$\mathrm{U}$ (5680-11,360 mg) for $>100 \mathrm{mg} \mathrm{Hb} / \mathrm{dL}$ (4000 mg Hp/50 kg, Yoshioka et al., 1985; Imaizumi et al., 1994).

Two clinical studies provide evidence that low plasma HPX levels at the time of diagnosis are related to the severity of sepsis and indicate a poor prognosis for septic shock. The criteria for sepsis diagnosis used the parameters defined by the American College of Chest Physicians Society of Critical Care Medicine consensus criteria (Moreno et al., 1999). In general, the patients received currently accepted methods of therapy including aggressive fluid resuscitation, broad-spectrum antibiotics during the first $24 \mathrm{~h}$, vasoactive agents; together with one or more doses of hydrocortisone. The mean initial HPX plasma levels in non-survivors $(\sim 0.6 \mathrm{mg} / \mathrm{ml})$ were significantly lower than those of the survivors (mean $\sim 1.2 \mathrm{mg} / \mathrm{ml}$; Larsen et al., 2010). In a similar study in Korea, initial serum HPX level in non-survivors was $0.75 \mathrm{mg} / \mathrm{ml}$ compared with $1.02 \mathrm{mg} / \mathrm{mL}(P<$ 0.001 ) in survivors (Jung et al., 2015). Thus, based on our current knowledge of how heme toxicity develops, there is every reason to believe that HPX infusions alone, or together with Hp, would be therapeutic in the management of sepsis, septic, and hemorrhagic shock (see Figure 2).

These clinical sepsis data showing that low HPX predicts a poor prognosis provide a rationale for investigating the role of HPX infusions as a therapy for HPX deficiency states secondary to sepsis-induced hemolysis. The first compelling observations that (i) heme toxicity can be central to the pathogenesis of a human disease allowing heme toxicity to develop as HPX levels decline (i.e., a HPX deficiency state); and (ii) HPX infusions restore circulating HPX levels, reduced mortality, and thus may be a novel therapeutic approach came from studies using mice models of sepsis (Larsen et al., 2010). The foundation was research with $\mathrm{Hmox}^{-/-}$mice, which revealed that HO-1 induction and heme catabolism in response to microbial infection suppressed the development of severe sepsis. Protection was found to be unrelated to the extent of the pathogen load but was related to protection against free heme released by hemolysis during the infection. Thus, non-protein bound heme compromised the host tolerance to infection.

Protection against heme toxicity by HPX also requires HOs and their enzyme activity because protection against heme and heme plus ROS is lost in $\mathrm{HO}-1^{-/-}$neurons and when HO-1 activity is inhibited by tin-protoporphyrinIX (Li et al., 2009). Although protection against redox-active iron was not part of the studies, earlier work (see Section Coordination of Extracellular and Intracellular Defenses May Be Needed under Specific Circumstances to Survive Heme Toxicity) and extended more recently (Vercellotti et al., 2014) showed a key role for the ferroxidase $\mathrm{H}$-ferritin subunit in spleen and liver to protect cells in SCD mice; but considered independent of HO-1 activity (Vercellotti et al., 2014).

Necrosis after toxic heme levels requires several hours so cells initially appear normal and any responses to heme in the short term need to be distinguished from possible toxic effects that only become apparent much later (e.g., after $24 \mathrm{~h}$ ). HPX also protects cells from "heme sensitization," the apoptotic cytotoxic effect of heme that requires exposure of cells not only to heme but subsequently to pro-inflammatory molecules such as TNF. 


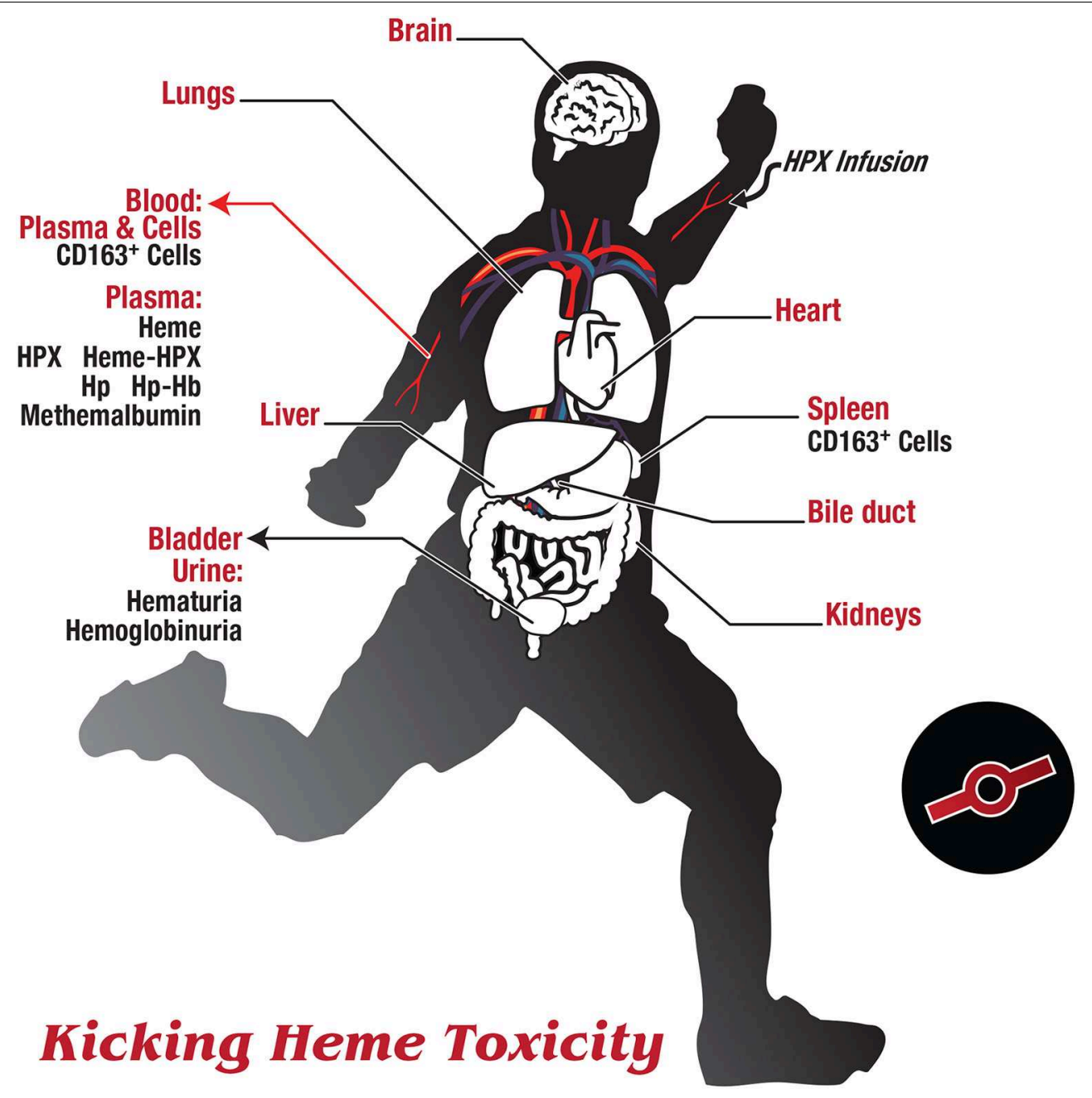

FIGURE 2 | Kicking heme toxicity. As originally suggested by Delanghe et al. (2010) and Drieghe et al. (2013), there is at the bedside a currently unrecognized and potentially quite frequent need to distinguish impaired heme clearance from ongoing hemolysis. Several major organs may be involved in the pathology of heme toxicity, including the liver, lungs, heart, spleen, intestine, and kidney. Certain immune-privileged sites such as the brain and gonads are initially protected by strong endothelial barriers with tight junctions, and certain immune-privileged cells exist in an immunosuppressive environment. Thus, endothelial cells provide a physical barrier and epithelial cells provide a selective cell gate. Several markers in blood and urine samples are indicated here, in addition to the standard liver and kidney function tests and parameters used for the hemolytic index. If routinely measured, e.g., free heme, free HPX and free Hp in plasma, and heme in urine should prove useful in diagnosis and help discern when there is impaired heme clearance due to a HPX deficiency state. As endothelial cells die and lyse they may be the principal source of plasma HO1 (Ghosh et al., 2011) and also raise LDH levels (Drieghe et al., 2013). The soluble ectodomain (sed) of scavenger receptors are released into the circulation by proteolysis and it is expected that sedCD163 will bind $\mathrm{Hb}$ and/or $\mathrm{Hp}-\mathrm{Hb}$, and sedLRP1/CD91 may bind heme-HPX.
Uptake of heme-HPX by primary human or mouse hepatocytes did not raise ROS levels as did heme, even after subsequent incubation with TNF for $16 \mathrm{~h}$ (Larsen et al., 2010). TNF alone raised release of HMGB1 from these primary hepatocytes and this was exacerbated by previous incubation with heme but not with heme bound to HPX. Thus, HPX prevents direct cytotoxicity of heme and heme sensitization of cells that is one consequence of heme exposure.

Low-grade sepsis in response to colon puncture and ligation is toxic in $\mathrm{Hmox} 1^{-/-}$mice but not WT mice $\left(\operatorname{Hmox} 1^{+/+}\right)$and i.v. heme promotes tissues damage and leads to a severe "high grade" sepsis (Larsen et al., 2010). This takes place although the levels of cytokines produced in the septic inflammatory response e.g., TNF, IL-6, and IL-10, were similar in Hmox1 ${ }^{-/-}$ and WT mice. $\mathrm{Hb}$ levels were above normal in $\mathrm{Hmox}^{-/-}$but not the $\mathrm{Hmox}^{-/+}$mice. Rodent models of human diseases where HPX and Hp are protective are complicated by the fact sham operations, stress, and inflammation alone can lead to significant increases in both HPX and Hp plasma levels. Nevertheless, the HPX levels were highest in the WT mice, decreased by about $20 \%$ in $\mathrm{Hmox}^{+/-}$(from $\sim 2.45$ to $2 \mathrm{mg} / \mathrm{ml}$ ) and had further decreased but were still detectable in the Hmox $1^{-/-}$mice Mice start to die as early as 2 days after CLP; however, HPX infusions (50 mg/kg ip) caused a significant decrease in this morbidity from 
75 to $20 \%$ when given at $2,12,24$, and $36 \mathrm{~h}$ post CLP. The control mice were given IgG ( $50 \mathrm{mg} / \mathrm{kg}$ ip) and an equal volume of the solvent control, PBS.

\section{Heme Toxicity in Hemorrhagic Shock and Links with Hemopexin}

Although hemorrhagic shock differs from septic shock (Wichterman et al., 1980), HPX metabolism is altered in hemorrhagic fever from Dengue virus, which is transmitted by infected mosquitoes. HPX levels were $10 \%$ of controls in severe dengue associated with hemorrhagic fever (DHF) and a rapid drop in platelets, during a dengue epidemic in Thailand (MullerEberhard and Liem, 1975). HPX levels may help determine the severity of the illness, discriminate between dengue hemorrhagic fever (DHF) and uncomplicated dengue fever (DF), which would aid in diagnosis and treatment; and fibronectin, HPX and transferrin were found to be significantly decreased in DHF (Kumar et al., 2012). In other studies, HPX and vitronectin were increased in DF and DHF (Poole-Smith et al., 2014). Although by no means proven [see references in (Poole-Smith et al., 2014) on data from other human and swine studies], HPX together with other biomarkers such as Hp, may prove useful as a supplement in certain stages of hemorrhagic shock and even, potentially in the progression of Ebola in patients, especially those that progress to hemorrhage.

\section{Improving Animal Models of Human Disease in which Hemopexin and Haptoglobin Play a Protective Role}

Experimental animals allow investigation of tissues not readily available in humans as well as greater control over response, sampling, and treatment times; thus, standardization is of prime importance in good animal models of human disease. The rhesus monkey (rhesus macaque, Macaca mulatta) is a primate model with the most similar genetics, physiology, and metabolism to humans. In contrast, with respect to the response to infection, mice can tolerate far larger burdens of bacteria than humans without succumbing and although this differential response can be bacterial species specific, there are differences between humans and mice in their response to inflammatory conditions (Seok et al., 2013). In mice and rats, HPX acts as an acute phase reactant and there are very rapid and extensive increases in plasma levels of HPX and Hp (e.g., 4-5-fold in inflammation) induced by a variety of stimuli including sham surgery. These are far higher than the $\sim 1.5-2$-fold changes documented in humans in various diseases and conditions. In general, animal plasma levels of HPX $(\mathrm{mg} / 100 \mathrm{ml})$ are similar to humans (Drabkin, 1971; Lane et al., 1973), e.g., rabbit (31-52), rat (63-82), and $\operatorname{dog}$ (76-128). However, in humans, HPX is not an acute phase reactant and was not induced by muscle biopsy that caused an inflammatory response raising $H p$ among other standard parameters e.g., fibrinogen and $\alpha_{1}$-antitrypsin (Elin et al., 1982).

Human HPX is a highly conserved glycoprotein and uniquely has an $\mathrm{N}$-terminal $\mathrm{O}$-linked oligosaccharide in addition to five bi-antennary chains (for review, see Smith, 2011b). Heme coordination is identical in human, rabbit, bovine, and rat HPX based on a variety of physic-chemical data including absorbance, electron paramagnetic resonance and magnetic circular dichroism spectroscopy. However, there are clear differences between the HPX and Hp systems in humans and in rats including species differences in receptor affinity.

One way forward to better understand the metabolism and the roles of HPX and Hp in humans is to compare directly the structure and function of human and mouse proteins and their receptor interactions in vivo and in cultured cells in vitro. Significant differences in the high affinity of human $\mathrm{Hp}-\mathrm{Hb}$ for human HuCD163 compared with that of mouse $\mathrm{Hp}-\mathrm{Hb}$ for mouse CD163; and between the high affinity of mouse $\mathrm{Hb}$ for mouse CD163 compared with human Hb for human CD163 as well as in vivo uptake supported that in humans $\mathrm{Hb}$ clearance is principally via receptor-mediated uptake of $\mathrm{Hp}-\mathrm{Hb}$ but not in mice (Etzerodt et al., 2013). It would seem that additional studies in humans are still needed to determine the extent of involvement and relative contributions of the role of the liver and macrophages in $\mathrm{Hp}-\mathrm{Hb}$ clearance and at what times during the course of the development of disease-related pathology.

The normal plasma clearance in rats of human and rabbit HPX is faster than that of rat HPX (Liem, 1976). There are differences in the affinity of human, rabbit and rat HPX for rat hepatic HPX receptors that affects the rate of heme clearance from the circulation and the extent of liver heme uptake from ${ }^{59} \mathrm{Fe}$-heme bound to ${ }^{125} \mathrm{I}$-labeled human, rabbit or rat HPX in rats (Smith and Morgan, 1979). More complex was taken up and more heme delivered to the liver within $5-15 \mathrm{~min}$ in the order human $>$ rabbit $>$ rat HPX complexes supporting that human HPX has a higher affinity for the rat HPX receptors than rat HPX. All three species of HPX interact with a common receptor on liver cells because increasing the levels of circulating complexes, led to similar hepatic saturation levels $[\sim 200 \mathrm{pmol} / \mathrm{g}$ of liver for both rat and rabbit HPX (Smith and Morgan, 1978)]; and competitive inhibition studies showed that non-radiolabeled rabbit heme-HPX complexes blocked radiolabeled rat hemehemopexin uptake. In these experiments, no extensive catabolism of ${ }^{125}$ I-rabbit HPX occurred; supporting that the chloramine$\mathrm{T}$ iodination, carried out under oxidizing conditions, had not denatured the protein which would then have been rapidly degraded by the liver. Furthermore, the heme levels used were low enough to minimally affect HPX metabolism.

Endothelial cells are clearly a heme target in SCD; also HO1 is increased in renal tissues of SCD patients but not in the Townes and Berkeley mice model of SCD (that are on identical backgrounds, Ghosh et al., 2011). Circulating endothelial cells, shed from the vascular wall lining into the bloodstream, are rarely seen in normal individuals but are in SCD and may reflect vascular damage/dysfunction. The responses of cytoprotective enzymes to heme in vitro were found to vary depending upon the duration of heme exposure and origin of endothelial cells. Primary human endothelial cells from the pulmonary artery (PAECs) and microvasculature (PMVECs), and dermal microvasculature were incubated with multiple exposures to heme $(5-25 \mu \mathrm{M})$, considered not toxic, in fresh media every $48 \mathrm{~h}$ for 7 days. Five genes differentially regulated by heme in 
PMVECS and PAECs were shared: HO1, glutamate-cysteineligase modifier subunit, $\mathrm{NQO} 1, \mathrm{H}$-ferritin and $\delta$-aminolevulinate synthase 1. Nrf2 regulation was considered central: whereas HO1 was quickly induced by heme, NQO1 required several days and was apparent only in the older mice perhaps due to the oxidant burden of the disease and low levels of endothelial SOD. NQO1 staining was more intense in clinical SCD than in mice. One similarity between the mice and clinical SCD was the intensity of $\mathrm{HO} 1$ staining in post-mortem lung endothelium, although $\mathrm{HO} 1$ mRNA levels were highly variable in the patients. Plasma HO1 levels from SCD patients varied considerably, but correlated with markers of endothelial cell activation and injury. These enzyme changes may provide a strategy for additional SCD therapy (Ghosh et al., 2011).

Patients and rhesus monkeys were used to investigate why serum levels of HPX are abnormal in hemolytic anemias, chronic neuromuscular diseases, and acute intermittent porphyria. The synthetic and fractional catabolic rates of HPX were measured in patients exhibiting low, normal, or elevated serum HPX levels (Foidart et al., 1983). Elevated HPX levels principally reflected increased synthesis not decreased catabolism of HPX: the mean synthetic rate $(13 \pm 1.0 \mathrm{mg} / \mathrm{kg} /$ day $)$ was twice that of the patients with normal HPX levels $(6.6 \pm 0.3 \mathrm{mg} / \mathrm{kg} /$ day $)$, whereas the fractional catabolic rate was $\sim 33 \%$ higher than controls (i.e., $35.3 \pm 7.1 \%$ of the i.v. pool per day compared with $26.5 \pm 0.8$ for controls). Low serum HPX in patients with SCD appeared to be due to increased HPX catabolism (36.0 and $40.0 \%$ of the i.v. pool per day vs. $26.5 \pm 0.8$ for controls) without compensatory synthesis. Clinical conditions in which serum HPX levels are either increased (acute intermittent porphyria, chronic neuromuscular diseases) or decreased (severe hemolysis or rhabdomyolysis) were simulated in rhesus monkeys by administering heme i.v. daily over 10 days (Foidart et al., 1982). Low heme (0.02-0.04 mg/kg/day) increased serum HPX levels by $50 \%$ (control $=53.3 \pm 2.8 \mathrm{U} / 100 \mathrm{ml}$ ) due to a $76 \%$ increase in the net rate of HPX synthesis, that enlarged the IVH pool size of HPX by $65 \%$. An intermediate heme dose $(0.6 \mathrm{mg} / \mathrm{kg} /$ day $)$ caused a $43 \%$ increase in the rate of HPX synthesis balanced by a $33 \%$ increase in catabolism; and HPX serum levels were unchanged. High heme $(5.0 \mathrm{mg} / \mathrm{kg} /$ day $)$ decreased HPX to $60 \%$ of control due to a $57 \%$ increase in HPX catabolism without a concurrent increase in synthesis. HPX metabolism reached steady state within 4 days of heme exposure; and both ${ }^{125}$ I-human and monkey HPX were metabolized in the same way. HPX was specifically regulated by heme because plasma transferrin and $\mathrm{Hp}$ were unaltered. These findings support a relationship between the amount of heme presented to the liver and net HPX turnover; and implicated, for the first time, a role for hepatic heme levels in HPX regulation. Consistent with these observations, heme induces HPX mRNA in murine hepatoma cells (Smith, 1999) and primary embryonic rat neurons (He et al., 2010). From other studies but relevant here, raising plasma heme did not alter the half-life of HSA as it does HPX. Furthermore, HSA was cleared faster than rabbit albumin with half-lives of ${ }^{125} \mathrm{I}$ HSA and heme- ${ }^{125}$ I-HSA compared with rabbit albumin and heme-rabbit albumin [3.25-3.75 days compared with 4.5-5.25 days (Liem et al., 1975)].
This research in monkeys demonstrates the advantage of investigating the response of HPX to a wide range of heme concentrations based upon human studies, especially low levels. Most studies use a single, pharmacologically toxic high heme dose, e.g., a 50-fold excess of theoretical/possible HPX binding (Lane et al., 1973). Heme is a normal constituent of bile in humans $12.6 \mathrm{nmol} / \mathrm{h}$ compared with $8.2 \mu \mathrm{mol} / \mathrm{h}$ bilirubin. Heme administration $(6.4 \mu \mathrm{mol} / \mathrm{kg})$ increases heme $(109.5 \mathrm{nmol} / \mathrm{h})$ not bilirubin (McCormack et al., 1982). Higher amounts of heme administered i.p. in rats (5-40 mg/kg body weight) causes bile to turn black [heme at $0.29 \mathrm{mg} / \mathrm{ml}$ (Petryka et al., 1977)]. However, whether this is due to unregulated diffusion via the FLVCR heme exporter or a normal entero-hepatic circulation of heme is not established. In rats, at low doses of heme $(47 \mathrm{nmol} / 100$ g body weight) based upon $10 \times$ the daily heme requirement of humans relative to body weight, there is extensive heme catabolism in duodenal enterocytes. Because only iron reached the circulation bound to transferrin, no heme-HPX was detectable, these data revealed that duodenal enterocytes are the first point of convergence of heme and iron metabolism in the body (Smith, 1990, 2009, 2011b).

The genetic background of mice affects their iron status, and the iron status of mice and their strain affects Hp expression in different ways depending upon the response of the ER unfolded protein pathway to iron load (Faye et al., 2007). There was a significant decrease in liver and serum Hp in C57BL6 mice but not the $129 \mathrm{sv}$ strain, fed an iron-rich diet. The chaperone for protein folding in the ER, glucose regulated protein, GRP78, was decreased in the C57BL6, but not in the 129sv, mice. Iron overload negatively impacted Hp synthesis likely by creating oxidative stress in the ER. Then incorrectly processed and folded Hp is degraded upon GRP78 depletion. It is not known if this affects the metabolism of $\mathrm{Hp}$, whose regulation is stabilized in the $\mathrm{HPX}^{-/-}$mice (Tolosano et al., 1999), which are on the 129sv background.

Overall, these animal studies demonstrate and re-inforce the conservation across species of the protective role of HPX against heme toxicity, the development of HPX deficiency states, and show how raising heme and iron levels in the liver makes an impact on HPX and Hp synthesis and metabolism.

\section{Concluding Remarks}

In this article we have outlined the deleterious physiological consequences of IVH free heme and the role these effects play in the development and complications of various disease processes in humans. HPX's actions, biological roles, metabolism, and function have also been studied in rhesus monkeys, dogs, rabbits, rats, and $\mathrm{HPX}^{-/-}$mice (Tolosano et al., 1999, 2002; Morello et al., 2007; Fagoonee et al., 2008; Vinchi et al., 2008; Li et al., 2009; Chen et al., 2011).

Relevant to human disease: (1) HPX sequesters heme from cells preventing direct cytotoxicity and heme sensitization; and in cells lacking HPX receptors this prevents endothelial and immune cell activation leading to stasis and exacerbation of the inflammatory response, respectively; (2) Plasma HPX targets heme principally to the liver and normally recycles intact after 
receptor-mediated endocytosis while the heme is degraded and its iron re-claimed; (3) Hepatic uptake of heme-HPX is via a high affinity low capacity system, likely LRP1/CD91, and a low affinity high capacity system (Smith and Morgan, 1981; Smith, 2013); (4) Heme transfers rapidly in plasma from albumin to HPX; (5) Plasma HPX levels are linked to plasma and hepatic heme, not plasma $\mathrm{Hb}$ levels or the acute phase response; (6) Changes in plasma HPX levels reflect the balance of hepatic synthesis and secretion of HPX with HPX catabolism; HPX declines with increased hepatic heme as HPX catabolism overshadows compensatory synthesis; (8) HPX metabolism responds to heme from $\mathrm{Hb}$ and $\mathrm{Mb}$; (9) HPX protects erythrophagocytosing macrophages from heme toxicity in EVH; (10) HPX functions independently of and simultaneously with $\mathrm{Hp}$ and does not require global $\mathrm{Hp}$ depletion. As we strive to improve animal models, two current challenges to accurately describing $\mathrm{Hb}$ metabolism lie in the differences in $\mathrm{Hb}-\mathrm{Hp}$ metabolism in $\mathrm{CD}_{163^{+}}$human macrophages compared with these cells in mice and the lack of a reliable, high throughput assay to detect and quantitate in plasma $\mathrm{Hb}-\mathrm{Hp}$, heme-HPX, and methemalbumin.

Incorporating this contemporary understanding of heme metabolism into the evaluation of disease states prominently characterized by hemolysis may likely prove valuable in a variety of ways, including: (1) providing accurate diagnosis of acute illness; (2) improving our ability to determine which patients are at greater risk for more severe illness, complications, or death; and (3) developing targeted replenishment therapies for patients suffering from acute illnesses due to, or exacerbated by, significant hemolysis. However, large gaps remain in our understanding of heme metabolism and the role that HPX and $\mathrm{Hp}$ could play in specific disease states. In addition to the benchside experiments using animal models that have provided much of the knowledge to date on the roles of HPX and Hp in heme and $\mathrm{Hb}$ metabolism, respectively, translational approaches that use human-derived samples from patients with and without specific diseases and/or risk factors are warranted.

Future studies in human subjects should focus on several common diseases that often feature, or are complicated by, hemolysis. These diseases include SCD, sepsis, hemolytic anemias, and viral hemorrhagic fevers (e.g., Dengue, Ebola, and

\section{References}

Adornato, B. T., Kagen, L. J., Garver, F. A., and Engel, W. K. (1978). Depletion of serum hemopexin in fulminant rhabdomyolysis evidence for an interaction of hemopexin with myoglobin- derived heme. Arch. Neurol. 35, 547-548. doi: 10.1001/archneur.1978.00500320067016

Aird, W. C. (2005). Spatial and temporal dynamics of the endothelium. J. Thromb. Haemost. 3, 1392-1406. doi: 10.1111/j.1538-7836.2005.01328.x

Akerstrom, B., and Gram, M. (2014). A1M, an extravascular tissue cleaning and housekeeping protein. Free Radic. Biol. Med. 74, 274-282. doi: 10.1016/j.freeradbiomed.2014.06.025

Alam, J., and Smith, A. (1989). Receptor-mediated transport of heme by hemopexin regulates gene expression in mammalian cells. J. Biol. Chem. 264, 17637-17640.

Almog, C., Isakov, A., Ayalon, D., Burke, M., and Shapira, I. (1987). Serum myoglobin in detection of myocardial necrosis in patients with "coronary insufficiency." Clin. Cardiol. 10, 347-349. doi: 10.1002/clc.4960100510
Marburg). Sepsis and SCD in particular have readily-available animal models and baseline data, and disease incidence is sufficiently common to allow both acute and longitudinal studies in humans. Future studies should be conducted to determine HPX levels in these disease states, to assess the discriminatory ability of HPX for disease in symptomatic and/or at-risk individuals, and to determine the prognostic utility of obtaining HPX levels in acutely-ill patients. When assessing severe illness characterized by prominent hemolysis, physicians currently use hematological profiles that quantitate cellular components and measure coagulation function. We propose that including plasma heme and HPX measurements as adjuncts to these standard hematological assays may further enhance the diagnostic and prognostic capabilities of the hematological profile, thereby enhancing clinical decision-making. An international standard for plasma heme and HPX, as previously suggested (Delanghe and Langlois, 2001), is called for and will make defining heme toxicity risk more accessible and easier to interpret. Finally, many disease states characterized prominently by hemolysis lack targeted therapies. Investigating the role of replenishment therapies, particularly with HPX to sequester heme, may prove beneficial for these patients and in a plethora of clinical situations including cardiac surgery, blood transfusions, and patients with a high risk of developing sepsis (e.g., with burns, trauma injury, bed sores in the intensive care units or who have alcoholism).

\section{Author Contributions}

Both authors wrote and edited the manuscript; AS designed the figures.

\section{Acknowledgments}

The authors are indebted to Mr. Joseph Cook (Marketing and Communications, UMKC School of Medicine) for his artistic rendering of the schematic figures and his patience. The research of the authors has been supported by the National Institutes of Health (AS), the American Heart Association (AS), the UM Research Board (AS), the Thrasher Foundation (RM), and The Gerber Foundation (RM).
Andersen, C. B., Torvund-Jensen, M., Nielsen, M. J., De Oliveira, C. L., Hersleth, H. P., Andersen, N. H., et al. (2012). Structure of the haptoglobin-haemoglobin complex. Nature 489, 456-459. doi: 10.1038/nature11369

Balla, G., Jacob, H. S., Balla, J., Rosenberg, M., Nath, K., Apple, F., et al. (1992). Ferritin: a cytoprotective antioxidant strategem of endothelium. J. Biol. Chem. 267, 18148-18153.

Balla, G., Jacob, H. S., Eaton, J. W., Belcher, J. D., and Vercellotti, G. M. (1991a). Hemin: a possible physiological mediator of low density lipoprotein oxidation and endothelial injury. Arterioscler. Thromb. 11, 1700-1711. doi: 10.1161/01.ATV.11.6.1700

Balla, G., Vercellotti, G. M., Muller-Eberhard, U., Eaton, J., and Jacob, H. S. (1991b). Exposure of endothelial cells to free heme potentiates damage mediated by granulocytes and toxic oxygen species. Lab. Invest. 64, 648-655.

Balla, J., Jacob, H. S., Balla, G., Nath, K., Eaton, J. W., and Vercellotti, G. M. (1993). Endothelial-cell heme uptake from heme proteins: induction of sensitization and desensitization to oxidant damage. Proc. Natl. Acad. Sci. U.S.A. 90, 9285-9289. doi: 10.1073/pnas.90.20.9285 
Baumann, H., Morella, K. K., Jahreis, G. P., and Marinkovic, S. (1990). Distinct regulation of the interleukin-1 and interleukin- 6 response elements of the rat haptoglobin gene in rat and human hepatoma cells. Mol. Cell. Biol. 10, 5967-5976.

Belcher, J. D., Chen, C., Nguyen, J., Milbauer, L., Abdulla, F., Alayash, A. I., et al. (2014). Heme triggers TLR4 signaling leading to endothelial cell activation and vaso-occlusion in murine sickle cell disease. Blood 123, 377-390. doi: 10.1182/blood-2013-04-495887

Bui, L., Rish, K., Jaronczyk, K., Bourque, S., Mclaughlin, B. E., Brien, J. F., et al. (2004). The source of heme for vascular heme oxygenase I: heme uptake in rat aorta. Can. J. Physiol. Pharmacol. 82, 209-217. doi: 10.1139/y04-014

Bunn, H. F., and Jandl, J. H. (1968). Exchange of heme among hemoglobins and between hemoglobin and albumin. J. Biol. Chem. 243, 465-475.

Camejo, G., Halberg, C., Manschik-Lundin, A., Hurt-Camejo, E., Rosengren, B., Olsson, H., et al. (1998). Hemin binding and oxidation of lipoproteins in serum: mechanisms and effect on the interaction of LDL with human macrophages. J. Lipid Res. 39, 755-766.

Chen, G., Zhang, D., Fuchs, T. A., Manwani, D., Wagner, D. D., and Frenette, P. S. (2014). Heme-induced neutrophil extracellular traps contribute to the pathogenesis of sickle cell disease. Blood 123, 3818-3827. doi: 10.1182/blood2013-10-529982

Chen, L., Zhang, X., Chen-Roetling, J., and Regan, R. F. (2011). Increased striatal injury and behavioral deficits after intracerebral hemorrhage in hemopexin knockout mice. J. Neurosurg. 114, 1159-1167. doi: 10.3171/2010.10.JNS10861

Chen, W., Lu, H., Dutt, K., Smith, A., Hunt, D. M., and Hunt, R. C. (1998). Expression of the protective proteins hemopexin and haptoglobin by cells of the neural retina. Exp. Eye Res. 67, 83-93. doi: 10.1006/exer.1998.0494

Connor, J. R., and Menzies, S. L. (1996). Relationship of iron to oligodendrocytes and myelination. Glia 17, 83-93.

Davies, D. M., Smith, A., Muller-Eberhard, U., and Morgan, W. T. (1979). Hepatic subcellular metabolism of heme from heme-hemopexin: incorporation of iron into ferritin. Biochem. Biophys. Res. Commun. 91, 1504-1511. doi: 10.1016/0006-291X(79)91235-X

Delanghe, J. R., and Langlois, M. R. (2001). Hemopexin: a review of biological aspects and the role in laboratory medicine. Clin. Chim. Acta 312, 13-23. doi: 10.1016/S0009-8981(01)00586-1

Delanghe, J. R., and Langlois, M. R. (2002). Haptoglobin polymorphism and body iron stores. Clin. Chem. Lab. Med. 40, 212-216. doi: 10.1515/CCLM.2002.035

Delanghe, J. R., Langlois, M. R., Boelaert, J. R., Van Acker, J., Van Wanzeele, F., Van Der Groen, G., et al. (1998). Haptoglobin polymorphism, iron metabolism and mortality in HIV infection AIDS 12, 1027-1032. doi: 10.1097/00002030199809000-00010

Delanghe, J. R., Philippé, J., Moerman, F., De Buyzere, M. L., Vynckier, L. L., Verstraete, A. G., et al. (2010). Impaired hemoglobin scavenging during an acute HIV-1 retroviral syndrome. Clin. Chim. Acta 411, 521-523. doi: 10.1016/j.cca.2010.01.006

Drabkin, D. L. (1971). Heme binding and transport-a spectrophotometric study of plasma glycoglobulin hemochromogens. Proc. Natl. Acad. Sci. U.S.A. 68, 609-613. doi: 10.1073/pnas.68.3.609

Drieghe, S., Stove, V., Decruyenaere, J., and Delanghe, J. (2013). Interpretation of hemolysis tests following administration of a second-generation hemoglobin-based oxygen carrier. Acta Clin. Belg. 68, 282-286. doi: 10.2143/ ACB.3309

Elin, R. J., Foidart, M., Adornato, B. T., Engel, W. K., and Gralnick, H. R. (1982). Quantification of acute phase reactants after muscle biopsy. J. Lab. Clin. Med. 100, 566-573.

Etzerodt, A., Kjolby, M., Nielsen, M. J., Maniecki, M., Svendsen, P., and Moestrup, S. K. (2013). Plasma clearance of hemoglobin and haptoglobin in mice and effect of CD163 gene targeting disruption. Antioxid. Redox Signal. 18, 2254-2263. doi: 10.1089/ars.2012.4605

Eyster, M. E., Edgington, T. S., Liem, H. H., and Muller-Eberhard, U. (1972). Plasma hemopexin levels following aortic valve replacement: a valuable screening test for assessing the severity of cardiac hemolysis. J. Lab. Clin. Med. $80,112-116$

Fabriek, B. O., Van Bruggen, R., Deng, D. M., Ligtenberg, A. J., Nazmi, K., Schornagel, K., et al. (2009). The macrophage scavenger receptor CD163 functions as an innate immune sensor for bacteria. Blood 113, 887-892. doi: 10.1182/blood-2008-07-167064
Fagoonee, S., Caorsi, C., Giovarelli, M., Stoltenberg, M., Silengo, L., Altruda, F., et al. (2008). Lack of plasma protein hemopexin dampens mercuryinduced autoimmune response in mice. J. Immunol. 181, 1937-1947. doi: 10.4049/jimmunol.181.3.1937

Faye, A., Ramey, G., Foretz, M., and Vaulont, S. (2007). Haptoglobin is degraded by iron in C57BL/6 mice: a possible link with endoplasmic reticulum stress. Blood Cells Mol. Dis. 39, 229-237. doi: 10.1016/j.bcmd.2007.05.008

Figueiredo, R. T., Fernandez, P. L., Mourao-Sa, D. S., Porto, B. N., Dutra, F. F., Alves, L. S., et al. (2007). Characterization of heme as activator of Tolllike receptor 4. J. Biol. Chem. 282, 20221-20229. doi: 10.1074/jbc.M6107 37200

Foidart, M., Eiseman, J., Engel, W. K., Adornato, B. T., Liem, H. H., and MullerEberhard, U. (1982). Effect of heme administration on hemopexin metabolism in the rhesus monkey. J. Lab. Clin. Med. 100, 451-460.

Foidart, M., Liem, H. H., Adornato, B. T., Engel, W. K., and Muller-Eberhard, U. (1983). Hemopexin metabolism in patients with altered serum levels. J. Lab. Clin. Med. 102, 838-846.

Fortes, G. B., Alves, L. S., De Oliveira, R., Dutra, F. F., Rodrigues, D., Fernandez, P. L., et al. (2012). Heme induces programmed necrosis on macrophages through autocrine TNF and ROS production. Blood 119, 2368-2375. doi: 10.1182/blood-2011-08-375303

Frey, C. F. (1979). Hemorrhagic pancreatitis. Am. J. Surg. 137, 616-623. doi: 10.1016/0002-9610(79)90034-5

Friedman-Mor, Z., Chalon, J., Gorstein, F., Turndorf, H., Chuba, J. V., and Orkin, L. R. (1978). Abnormal heme-protein patterns in hemorrhagic shock. J. Trauma. 18, 104-107. doi: 10.1097/00005373-197802000-00005

Garby, L., and Noyes, W. D. (1959). J. Clin. Invest. 38, 1479-1488. doi: $10.1172 / \mathrm{JCI} 103925$

Ghosh, S., Adisa, O. A., Chappa, P., Tan, F., Jackson, K. A., Archer, D. R., et al. (2013). Extracellular hemin crisis triggers acute chest syndrome in sickle mice. J. Clin. Invest. 123, 4809-4820. doi: 10.1172/JCI64578

Ghosh, S., Tan, F., Yu, T., Li, Y., Adisa, O., Mosunjac, M., et al. (2011). Global gene expression profiling of endothelium exposed to heme reveals an organ-specific induction of cytoprotective enzymes in sickle cell disease. PLoS ONE 6:e18399. doi: 10.1371/journal.pone.0018399

Ghuman, J., Zunszain, P. A., Petitpas, I., Bhattacharya, A. A., Otagiri, M., and Curry, S. (2005). Structural basis of the drug-binding specificity of human serum albumin. J. Mol. Biol. 353, 38-52. doi: 10.1016/j.jmb.2005. 07.075

Giles, F. J., Kantarjian, H. M., Kornblau, S. M., Thomas, D. A., Garcia-Manero, G., Waddelow, T. A., et al. (2001). Mylotarg (gemtuzumab ozogamicin) therapy is associated with hepatic venoocclusive disease in patients who have not received stem cell transplantation. Cancer 92, 406-413. doi: 10.1002/10970142(20010715)92:2<406::AID-CNCR1336>3.0.CO;2-U

Gladwin, M. T., and Ofori-Acquah, S. F. (2014). Erythroid DAMPs drive inflammation in SCD. Blood 123, 3689-3690. doi: 10.1182/blood-2014-03563874

Graca-Souza, A. V., Arruda, M. A., De Freitas, M. S., Barja-Fidalgo, C., and Oliveira, P. L. (2002). Neutrophil activation by heme: implications for inflammatory processes. Blood 99, 4160-4165. doi: 10.1182/blood.V99.11.4160

Gutteridge, J. M., and Smith, A. (1988). Antioxidant protection by haemopexin of haem-stimulated lipid peroxidation. Biochem. J. 256, 861-865.

Hahl, P., Davis, T., Washburn, C., Rogers, J. T., and Smith, A. (2013). Mechanisms of neuroprotection by hemopexin: modeling the control of heme and iron homeostasis in brain neurons in inflammatory states. J. Neurochem. 125, 89-101. doi: $10.1111 /$ jnc. 12165

Halliwell, B., and Gutteridge, J. M. (1990). The antioxidants of human extracellular fluids. Arch. Biochem. Biophys. 280, 1-8. doi: 10.1016/0003-9861(90)90510-6

Hanstein, A., and Muller-Eberhard, U. (1968). Concentration of serum hemopexin in healthy children and adults and in those with a variety of hematological disorders. J. Lab. Clin. Invest. 71, 232-239.

He, Y., Hua, Y., Lee, J. Y., Liu, W., Keep, R. F., Wang, M. M., et al. (2010). Brain alpha- and beta-globin expression after intracerebral hemorrhage. Transl. Stroke Res. 1, 48-56. doi: 10.1007/s12975-009-0004-x

Hebbel, R. P., Morgan, W. T., Eaton, J. W., and Hedlund, B. E. (1988). Accelerated autoxidation and heme loss due to instability of sickle hemoglobin. Proc. Natl. Acad. Sci. U.S.A. 85, 237-241. doi: 10.1073/pnas.85.1.237 
Homann, B., Kult, J., and Weis, K. H. (1977). [On the use of concentrated haptoglobin in the treatment of a haemolytic transfusion accident of the ABO-system (author's transl)]. Anaesthesist 26, 485-488.

Hrkal, Z., Vodrazka, Z., and Kalousek, I. (1974). Transfer of heme from ferrihemoglobin and ferrihemoglobin isolated chains to hemopexin. Eur. J. Biochem. 43, 73-78. doi: 10.1111/j.1432-1033.1974.tb03386.x

Hunt, R. C., Hunt, D. M., Gaur, N., and Smith, A. (1996). Hemopexin in the human retina: protection of the retina against heme-mediated toxicity. J. Cell Physiol. $168,71-80$.

Hvidberg, V., Maniecki, M. B., Jacobsen, C., Hojrup, P., Moller, H. J., and Moestrup, S. K. (2005). Identification of the receptor scavenging hemopexinheme complexes. Blood 106, 2572-2579. doi: 10.1182/blood-2005-03-1185

Imaizumi, H., Tsunoda, K., Ichimiya, N., Okamoto, T., and Namiki, A. (1994). Repeated large-dose haptoglobin therapy in an extensively burned patient: case report. J. Emerg. Med. 12, 33-37. doi: 10.1016/0736-4679(94)90009-4

Jeney, V., Balla, J., Yachie, A., Varga, Z., Vercellotti, G. M., Eaton, J. W., et al. (2002). Pro-oxidant and cytotoxic effects of circulating heme. Blood 100, 879-887. doi: 10.1182/blood.V100.3.879

Jung, J. Y., Kwak, Y. H., Kim, K. S., Kwon, W. Y., and Suh, G. J. (2015). Change of hemopexin level is associated with the severity of sepsis in endotoxemic rat model and the outcome of septic patients. J. Crit. Care 30, 525-530. doi: 10.1016/j.jcrc.2014.12.009

Kondo, H., Saito, K., Grasso, J. P., and Aisen, P. (1988). Iron metabolism in the erythrophagocytosing Kupffer cell. Hepatology 8, 32-38. doi: 10.1002/hep. 1840080108

Kovtunovych, G., Eckhaus, M. A., Ghosh, M. C., Ollivierre-Wilson, H., and Rouault, T. A. (2010). Dysfunction of the heme recycling system in heme oxygenase 1-deficient mice: effects on macrophage viability and tissue iron distribution. Blood 116, 6054-6062. doi: 10.1182/blood-2010-03-272138

Kovtunovych, G., Ghosh, M. C., Ollivierre, W., Weitzel, R. P., Eckhaus, M. A., Tisdale, J. F., Yachie, A., et al. (2014). Wild-type macrophages reverse disease in heme oxygenase 1-deficient mice. Blood 124, 1522-1530. doi: 10.1182/blood2014-02-554162

Kumar, Y., Liang, C., Bo, Z., Rajapakse, J. C., Ooi, E. E., and Tannenbaum, S. R. (2012). Serum proteome and cytokine analysis in a longitudinal cohort of adults with primary dengue infection reveals predictive markers of DHF. PLoS Negl. Trop. Dis. 6:e1887. doi: 10.1371/journal.pntd.0001887

Kushner, I., Edgington, T. S., Trimble, C., Liem, H. H., and Muller-Eberhard, U. (1972). Plasma hemopexin homeostasis during the acute phase response. J. Lab. Clin. Med. 80, 18-25.

Lane, R. S., Rangeley, D. M., Liem, H. H., Wormsley, S., and Muller-Eberhard, U. (1973). Plasma clearance of 125I-labelled haemopexin in normal and haem- loaded rabbits. Br. J. Haematol. 25, 533-540. doi: 10.1111/j.13652141.1973.tb01764.x

Lane, R. S., Rangeley, D. M., Liem, H., Wormsley, S., and Muller-Eberhard, U. (1972). Hemopexin metabolism in the rabbit. J. Lab. Clin. Med. 79, 935-941.

Langley, R. J., Tipper, J. L., Bruse, S., Baron, R. M., Tsalik, E. L., Huntley, J., et al. (2014). Integrative "omic" analysis of experimental bacteremia identifies a metabolic signature that distinguishes human sepsis from systemic inflammatory response syndromes. Am. J. Respir. Crit. Care Med. 190, 445-455. doi: $10.1164 / \mathrm{rccm} .201404-0624 \mathrm{OC}$

Langley, R. J., Tsalik, E. L., Van Velkinburgh, J. C., Glickman, S. W., Rice, B. J., Wang, C., et al. (2013). An integrated clinico-metabolomic model improves prediction of death in sepsis. Sci. Transl. Med. 5:195ra195. doi: 10.1126/scitranslmed.3005893

Larsen, R., Gozzelino, R., Jeney, V., Tokaji, L., Bozza, F. A., Japiassu, A. M., et al. (2010). A central role for free heme in the pathogenesis of severe sepsis. Sci. Transl. Med. 2:51ra71. doi: 10.1126/scitranslmed.3001118

Li, R. C., Saleem, S., Zhen, G., Cao, W., Zhuang, H., Lee, J., et al. (2009). Hemehemopexin complex attenuates neuronal cell death and stroke damage. J. Cereb. Blood Flow Metab. 29, 953-964. doi: 10.1038/jcbfm.2009.19

Liang, X., Lin, T., Sun, G., Beasley-Topliffe, L., Cavaillon, J. M., and Warren, H. S. (2009). Hemopexin down-regulates LPS-induced proinflammatory cytokines from macrophages. J. Leukoc. Biol. 86, 229-235. doi: 10.1189/jlb. 1208742

Liem, H. H. (1976). Catabolism of homologous and heterologous hemopexin in the rat and uptake of hemopexin by isolated perfused rat liver. Ann. Clin. Res. $8,233-238$.
Liem, H. H., Spector, J. I., Conway, T. P., Morgan, W. T., and Muller-Eberhard, U. (1975). Effect of hemoglobin and hematin on plasma clearance of hemopexin, photo-inactivated hemopexin and albumin (38575). Proc. Soc. Exp. Biol. Med. 148, 519-522. doi: 10.3181/00379727-148-38575

Lim, S. K., Ferraro, B., Moore, K., and Halliwell, B. (2001). Role of haptoglobin in free hemoglobin metabolism. Redox Rep. 6, 219-227. doi: $10.1179 / 135100001101536364$

Lull, M. E., Carkaci-Salli, N., Freeman, W. M., Myers, J. L., Midgley, F. M., Thomas, N. J., et al. (2008). Plasma biomarkers in pediatric patients undergoing cardiopulmonary bypass. Pediatr. Res. 63, 638-644. doi: 10.1203/PDR.0b013e31816e391f

Maniecki, M. B., Hasle, H., Friis-Hansen, L., Lausen, B., Nielsen, O. J., Bendix, K., et al. (2008). Impaired CD163-mediated hemoglobin-scavenging and severe toxic symptoms in patients treated with gemtuzumab ozogamicin. Blood 112, 1510-1514. doi: 10.1182/blood-2007-09-114165

Marro, S., Chiabrando, D., Messana, E., Stolte, J., Turco, E., Tolosano, E., et al. (2010). Heme controls ferroportin1 (FPN1) transcription involving Bach1, $\mathrm{Nrf} 2$ and a MARE/ARE sequence motif at position -7007 of the FPN1 promoter. Haematologica 95, 1261-1268. doi: 10.3324/haematol.2009.020123

May, K., Rosenlof, L., Olsson, M. G., Centlow, M., Morgelin, M., Larsson, I., et al. (2011). Perfusion of human placenta with hemoglobin introduces preeclampsia-like injuries that are prevented by alphal-microglobulin. Placenta 32, 323-332. doi: 10.1016/j.placenta.2011.01.017

McCarthy, R. C., and Kosman, D. J. (2014). Glial cell ceruloplasmin and hepcidin differentially regulate iron efflux from brain microvascular endothelial cells. PLOS ONE 9:e89003. doi: 10.1371/journal.pone.0089003

McCormack, L. R., Liem, H. H., Strum, W. B., Grundy, S. M., and Muller-Eberhard, U. (1982). Effects of haem infusion on biliary secretion of porphyrins, haem and bilirubin in man. Eur. J. Clin. Invest. 12, 257-262. doi: 10.1111/j.13652362.1982.tb01001.x

Morello, N., Bianchi, F. T., Marmiroli, P., Tonoli, E., Rodriguez Menendez, V., Silengo, L., et al. (2011). A role for hemopexin in oligodendrocyte differentiation and myelin formation. PLOS ONE 6:e20173. doi: 10.1371/journal.pone.0020173

Morello, N., Tonoli, E., Logrand, F., Fagoonee, S., Turco, E., Silengo, L., et al. (2007). "Brain iron accumulation and oxidative stress in hemopexin null mice," in European Iron Club London, 13-15 September.

Moreno, R., Vincent, J. L., Matos, R., Mendonca, A., Cantraine, F., Thijs, L., et al. (1999). The use of maximum SOFA score to quantify organ dysfunction/failure in intensive care. Results of a prospective, multicentre study. Working Group on Sepsis related Problems of the ESICM. Intensive Care Med. 25, 686-696. doi: 10.1007/s001340050931

Morris, C. M., Candy, J. M., Edwardson, J. A., Bloxham, C. A., and Smith, A. (1993). Evidence for the localization of haemopexin immunoreactivity in neurones in the human brain. Neurosci. Lett. 149, 141-144. doi: 10.1016/03043940(93)90756-B

Moss, D., Fargion, S., Fracanzani, A. L., Levi, S., Cappellini, M. D., Arosio, P., et al. (1992). Functional roles of the ferritin receptors of human liver, hepatoma, lymphoid and erythroid cells. J. Inorg. Biochem. 47, 219-227. doi: 10.1016/0162-0134(92)84067-W

Muller-Eberhard, U., and Cleve, H. (1963). Immunoelectrophoretic studies of the beta1-haem-binding globulin (haemopexin) in hereditary haemolytic disorders. Nature 197, 602-603. doi: 10.1038/197602a0

Muller-Eberhard, U., and Fraig, M. (1993). Bioactivity of heme and its containment. Am. J. Hematol. 42, 59-62. doi: 10.1002/ajh.2830420112

Muller-Eberhard, U., Javid, J., Liem, H. H., Hanstein, A., and Hanna, M. (1968). Plasma concentrations of hemopexin, haptoglobin and heme in patients with various hemolytic diseases. Blood 32, 811-815.

Muller-Eberhard, U., and Liem, H. H. (1975). Hemopexin, the heme binding serum b glycoprotein. La Ricercha Clin. Lab. 5, 275-291.

Muller-Eberhard, U., Liem, H. H., Hanstein, A., and Saarinen, P. A. (1969). Studies on the disposal of intravascular heme in the rabbit. J. Lab. Clin. Med. 73, $210-218$

Nagy, E., Eaton, J. W., Jeney, V., Soares, M. P., Varga, Z., Galajda, Z., et al. (2010). Red cells, hemoglobin, heme, iron, and atherogenesis. Arterioscler. Thromb. Vasc. Biol. 30, 1347-1353. doi: 10.1161/ATVBAHA.110.206433

Nemeth, E., Tuttle, M. S., Powelson, J., Vaughn, M. B., Donovan, A., Ward, D. M., et al. (2004). Hepcidin regulates cellular iron efflux by binding to 
ferroportin and inducing its internalization. Science 306, 2090-2093. doi: 10.1126/science. 1104742

Noyes, W. D., Bothwell, T. H., and Finch, C. A. (1960). The role of the reticulo-endothelial cell in iron metabolism. Br. J. Haematol. 6, 43-55. doi: $10.1111 /$ j.1365-2141.1960.tb06216.x

Oliviero, S., and Cortese, R. (1989). The human haptoglobin gene promoter: interleukin-6-responsive elements interact with a DNA-binding protein induced by interleukin-6. EMBO J. 8, 1145-1151.

Oliviero, S., Morrone, G., and Cortese, R. (1987). The human haptoglobin gene: transcriptional regulation during development and acute phase induction. EMBO J. 6, 1905-1912.

Paoli, M., Anderson, B. F., Baker, H. M., Morgan, W. T., Smith, A., and Baker, E. N. (1999). Crystal structure of hemopexin reveals a novel high-affinity heme site formed between two beta-propeller domains. Nat. Struct. Biol. 6, 926-931. doi: $10.1038 / 13294$

Petryka, Z. J., Pierach, C. A., Smith, A., Goertz, M. N., and Edwards, P. S. (1977). Biliary excretion of exogenous hematin in rats. Life Sci. 21, 1015-1020. doi: 10.1016/0024-3205(77)90269-7

Philippidis, P., Mason, J. C., Evans, B. J., Nadra, I., Taylor, K. M., Haskard, D. O., et al. (2004). Hemoglobin scavenger receptor CD163 mediates interleukin-10 release and heme oxygenase-1 synthesis: antiinflammatory monocyte-macrophage responses in vitro, in resolving skin blisters in vivo, and after cardiopulmonary bypass surgery. Circ. Res. 94, 119-126. doi: 10.1161/01.RES.0000109414.78907.F9

Polfliet, M. M., Fabriek, B. O., Daniels, W. P., Dijkstra, C. D., and van den Berg, T. K. (2006). The rat macrophage scavenger receptor CD163: expression, regulation and role in inflammatory mediator production. Immunobiology 211, 419-425. doi: 10.1016/j.imbio.2006.05.015

Poli, V., Oliviero, S., Morrone, G., and Cortese, R. (1989). Characterization of an IL-6-responsive element (IL6RE) present on liver-specific genes and identification of the cognate IL-6-dependent DNA-binding protein (IL6DBP). Ann. N. Y. Acad. Sci. 557, 297-309. doi: 10.1111/j.1749-6632.1989. tb24022.x

Poole-Smith, B. K., Gilbert, A., Gonzalez, A. L., Beltran, M., Tomashek, K. M., Ward, B. J., et al. (2014). Discovery and characterization of potential prognostic biomarkers for dengue hemorrhagic fever. Am. J. Trop. Med. Hyg. 91, 1218-1226. doi: 10.4269/ajtmh.14-0193

Ritter, M., Buechler, C., Kapinsky, M., and Schmitz, G. (2001). Interaction of CD163 with the regulatory subunit of casein kinase II (CKII) and dependence of CD163 signaling on CKII and protein kinase C. Eur. J. Immunol. 31, 999-1009. doi: 10.1002/1521-4141(200104)31

Sakata, S., Yoshioka, N., and Atassi, M. Z. (1986). Human haptoglobin binds to human myoglobin. Biochim. Biophys. Acta 873, 312-315. doi: 10.1016/01674838(86)90060-9

Sallach, S. M., Nowak, R., Hudson, M. P., Tokarski, G., Khoury, N., Tomlanovich, M. C., et al. (2004). A change in serum myoglobin to detect acute myocardial infarction in patients with normal troponin I levels. Am. J. Cardiol. 94, 864-867. doi: 10.1016/j.amjcard.2004.06.019

Schaer, D. J., Buehler, P. W., Alayash, A. I., Belcher, J. D., and Vercellotti, G. M. (2013). Hemolysis and free hemoglobin revisited: exploring hemoglobin and hemin scavengers as a novel class of therapeutic proteins. Blood 121, 1276-1284. doi: 10.1182/blood-2012-11-451229

Schaer, D. J., Vinchi, F., Ingoglia, G., Tolosano, E., and Buehler, P. W. (2014). Haptoglobin, hemopexin, and related defense pathways-basic science, clinical perspectives, and drug development. Front. Physiol. 5:415. doi: $10.3389 /$ fphys.2014.00415

Sears, D. (1999). Overview of Hemoglobin's Structure/Function Relationships. Available online at: http://mcdb-webarchive.mcdb.ucsb.edu/sears/ biochemistry/pdf/hbn-overview.pdf.

Sears, D. A. (1968). Plasma heme-binding in patients with hemolytic disorders. J. Lab. Clin. Med. 71, 484-494.

Sears, D. A. (1970). Disposal of plasma heme in normal man and patients with intravascular hemolysis. J. Clin. Invest. 49, 5-14. doi: 10.1172/JCI1 06222

Seok, J., Warren, H. S., Cuenca, A. G., Mindrinos, M. N., Baker, H. V., Xu, W., et al. (2013). Genomic responses in mouse models poorly mimic human inflammatory diseases. Proc. Natl. Acad. Sci. U.S.A. 110, 3507-3012. doi: $10.1073 /$ pnas. 1222878110
Sheftel, A. D., Kim, S. F., and Ponka, P. (2007). Non-heme induction of heme oxygenase-1 does not alter cellular iron metabolism. J. Biol. Chem. 282, 10480-10486. doi: 10.1074/jbc.M700240200

Smith, A. (1990). Biosynthesis of Heme and Chlorophylls, Chapter 9. New York, NY: McGraw-Hill Inc.

Smith, A. (1999). "Role of redox-active metals in the regulation of the metallothionein and heme oxygenase gene by heme and hemopexin," in Iron Metabolism. Inorganic Biochemistry and Regulatory Mechanisms of Iron Metabolism, eds G. C. Ferreira, J. J. G. Moura, and R. Franco (Weinheim: Wiley-VCH Publishing Co.), 65-93.

Smith, A. (2009). "Novel heme-protein interactions: some more radical than others," in Tetrapyrroles: Birth, Life and Death, eds M. J. Warren and A. G. Smith (Austin; New York: Landes Bioscience; Springer Science+Business, LLC), 184-207. doi: 10.1007/978-0-387-78518-9_11

Smith, A. (2011a). "Iron salvage pathways," in Iron Physiology and Pathophysiology in Humans, eds G. J. Anderson and G. D. Mclaren (New York, NY: Humana Press), 141-172.

Smith, A. (2011b). "Mechanisms of cytoprotection by hemopexin," in Handbook of Porphyrin Science. Biochemistry of Tetrapyrroles, eds K. M. Kadish, K. M. Smith, and R. Guilard (Singapore: World Scientific Publishing Co. Pte. Ltd.), 217-356.

Smith, A. (2013). "Protection against heme toxicity: hemopexin rules, OK?" in Handbook of Porphyrin Science, ed G. Ferreira (Singapore: World Scientific Publishing Co.), 311-338.

Smith, A., and Hunt, R. C. (1990). Hemopexin joins transferrin as representative members of a distinct class of receptor-mediated endocytic transport systems. Eur. J. Cell Biol. 53, 234-245.

Smith, A., and Ledford, B. E. (1988). Expression of the haemopexin-transport system in cultured mouse hepatoma cells. Links between haemopexin and iron metabolism. Biochem. J. 256, 941-950.

Smith, A., and Morgan, W. T. (1978). Transport of heme by hemopexin to the liver: evidence for receptor-mediated uptake. Biochem. Biophys. Res. Commun. 84, 151-157. doi: 10.1016/0006-291X(78)90276-0

Smith, A., and Morgan, W. T. (1979). Haem transport to the liver by haemopexin. Receptor-mediated uptake with recycling of the protein. Biochem. J. 182, 47-54.

Smith, A., and Morgan, W. T. (1981). Hemopexin-mediated transport of heme into isolated rat hepatocytes. J. Biol. Chem. 256, 10902-10909.

Sung, L., Morales, P., Shibata, M., Shipulina, N., and Smith, A. (2000). "Defenses against extracellular heme-mediated oxidative damage: use of iron and copper chelators to investigate the role of redox active iron, copper and heme in the hemopexin heme transport system," in Iron Chelators: New Development Strategies, eds D. G. Badman, R. J. Bergeron, and G. M. Brittenham (Sarotoga, FL: Saratoga Publishing Group), 67-86.

Tanaka, K., Kanamori, Y., Sato, T., Kondo, C., Katayama, Y., Yada, I., et al. (1991). Administration of haptoglobin during cardiopulmonary bypass surgery. ASAIO Trans. 37, M482-M483.

Tolosano, E., Cutufia, M. A., Hirsch, E., Silengo, L., and Altruda, F. (1996). Specific expression in brain and liver driven by the hemopexin promoter in transgenic mice. Biochem. Biophys. Res. Commun. 218, 694-703. doi: 10.1006/bbrc.1996.0124

Tolosano, E., Fagoonee, S., Hirsch, E., Berger, F. G., Baumann, H., Silengo, L., et al. (2002). Enhanced splenomegaly and severe liver inflammation in haptoglobin/hemopexin double-null mice after acute hemolysis. Blood 100, 4201-4208. doi: 10.1182/blood-2002-04-1270

Tolosano, E., Hirsch, E., Patrucco, E., Camaschella, C., Navone, R., Silengo, L., et al. (1999). Defective recovery and severe renal damage after acute hemolysis in hemopexin-deficient mice. Blood 94, 3906-3914.

Tsalik, E. L., Langley, R. J., Dinwiddie, D. L., Miller, N. A., Yoo, B., van Velkinburgh, J. C., et al. (2014). An integrated transcriptome and expressed variant analysis of sepsis survival and death. Genome Med. 6, 111. doi: 10.1186/s13073-014-0111-5

van den Heuvel, M. M., Tensen, C. P., Van As, J. H., van den Berg, T. K., Fluitsma, D. M., Dijkstra, C. D., et al. (1999). Regulation of CD 163 on human macrophages: cross-linking of CD163 induces signaling and activation. J. Leukoc. Biol. 66, 858-866.

Vercellotti, G. M., Khan, F. B., Nguyen, J., Chen, C., Bruzzone, C. M., Bechtel, H., et al. (2014). H-ferritin ferroxidase induces cytoprotective pathways and inhibits microvascular stasis in transgenic sickle mice. Front. Pharmacol. 5:79. doi: 10.3389/fphar.2014.00079 
Vinchi, F., Gastaldi, S., Silengo, L., Altruda, F., and Tolosano, E. (2008). Hemopexin prevents endothelial damage and liver congestion in a mouse model of heme overload. Am. J. Pathol. 173, 289-299. doi: 10.2353/ajpath.2008.071130

Vladutiu, A. O., and Kim, J. S. (1981). Absence of beta-globulin band in the serum protein electropherogram of a patient with liver disease. Clin. Chem. 27, 334-336.

Wang, B., Jenkins, J. R., and Trayhurn, P. (2005). Expression and secretion of inflammation-related adipokines by human adipocytes differentiated in culture: integrated response to TNF-alpha. Am. J. Physiol. Endocrinol. Metab. 288, E731-E740. doi: 10.1152/ajpendo.00475.2004

Wester-Rosenlof, L., Casslen, V., Axelsson, J., Edstrom-Hagerwall, A., Gram, M., Holmqvist, M., et al. (2014). A1M/alpha1-microglobulin protects from hemeinduced placental and renal damage in a pregnant sheep model of preeclampsia. PLoS ONE 9:e86353. doi: 10.1371/journal.pone.0086353

Wichterman, K. A., Baue, A. E., and Chaudry, I. H. (1980). Sepsis and septic shocka review of laboratory models and a proposal. J. Surg. Res. 29, 189-201. doi: 10.1016/0022-4804(80)90037-2

Yachie, A., Niida, Y., Wada, T., Igarashi, N., Kaneda, H., Toma, T., et al. (1999). Oxidative stress causes enhanced endothelial cell injury in human heme oxygenase-1 deficiency. J. Clin. Invest. 103, 129-135. doi: 10.1172/ JCI4165

Yang, Z., Philips, J. D., Doty, R. T., Giraudi, P., Ostrow, J. D., Tiribelli, C., et al. (2010). Kinetics and specificity of feline leukemia virus subgroup $C$ receptor (FLVCR) export function and its dependence on hemopexin. J. Biol. Chem. 285, 28874-28882. doi: 10.1074/jbc.M110.119131

Yoshioka, T., Sugimoto, T., Ukai, T., and Oshiro, T. (1985). Haptoglobin therapy for possible prevention of renal failure following thermal injury: a clinical study. J. Trauma 25, 281-287. doi: 10.1097/00005373-198504000-00001

Conflict of Interest Statement: The authors declare that the research was conducted in the absence of any commercial or financial relationships that could be construed as a potential conflict of interest.

Copyright (c) 2015 Smith and McCulloh. This is an open-access article distributed under the terms of the Creative Commons Attribution License (CC BY). The use, distribution or reproduction in other forums is permitted, provided the original author(s) or licensor are credited and that the original publication in this journal is cited, in accordance with accepted academic practice. No use, distribution or reproduction is permitted which does not comply with these terms. 